\title{
18. Changes in Inequality in Australia and the Redistributional Impacts of Taxes and Government Benefits
}

\author{
J Rob Bray
}

\section{Introduction}

This paper is concerned with trends in income inequality in Australia over recent decades and the impact of government taxes and benefits. It comprises three main sections. The first considers some of the broad changes which may have contributed to changes in the distribution of income; the second tracks shifts in the distribution of income; and the third considers the contribution of specific components of income, in particular government taxes and benefits, to the level and change in income inequality.

In presenting this as a quantitative analysis the paper utilises three main sources of data - the ABS Survey of Income and Housing (SIH), the ABS Household Expenditure Survey (HES) and the Household Income and Labour Dynamics Australia (HILDA) survey. ${ }^{1}$ There are several reasons for this. The first is as a simple test of the robustness of the findings, ensuring that these are not simply the artefact of any particular dataset. The second is that each of these data series can contribute some unique elements to the analysis. The HES provides the longest reliable time span and permits the analysis of extended measures of income; the SIH, while less long running than the HES, has been conducted more regularly over the period for which it is available; and HILDA, while having the shortest time span, is available annually and also enables the longitudinal analysis of trends.

For the most part the paper is concerned with the disposable incomes, that is the total cash income, including government cash transfers, less income tax, that households have available to them to enable their consumption of goods and services, and to save, or repay debts associated with earlier or later consumption.

\footnotetext{
1 This paper uses unit record data from the Household, Income and Labour Dynamics in Australia (HILDA) Survey. The HILDA Project was initiated and is funded by the Department of Families, Housing, Community Services and Indigenous Affairs (FaHCSIA) and is managed by the Melbourne Institute of Applied Economic and Social Research (Melbourne Institute). The findings and views reported in this paper, however, are those of the author and should not be attributed to either FaHCSIA or the Melbourne Institute.
} 
The data has been equivalised ${ }^{2}$ to take account of variations in the size and composition of the household. ${ }^{3}$ In the third section a wider measure of income is considered, taking into account the value of some non-cash benefits, indirect taxes and the value of owner-occupied housing.

\section{Is income an adequate basis for considering inequality?}

While income is perhaps the most frequent focus for the study of inequality, at least in western countries, it is far from being the only variable that can, or indeed should be, considered. Although usually seen as a measure of the capacity of individuals to support their consumption, the relationship between income and consumption, while present, is often far from complete, especially in survey data.

Table 1 shows the correlations between equivalised disposable income and a range of other measures of household income, consumption, wealth ${ }^{4}$ and wellbeing. While all of the correlations between the different measures of income, consumption and wealth are positive and robust, and those between these and the measures of adverse outcomes, such as financial stress and hardship, are robust and negative, the coefficient values are quite low given the extent to which the concepts are frequently considered to be synonymous.

A consequence of these results is, as noted above, that considerable caution needs to be exercised in the interpretation of data on income inequality. While low levels of measured income may be associated with low levels of consumption and low wealth, for many this is not the case. It can also be suggested that a change in the distribution of any one of these may not necessarily be reflected in the others.

2 In this paper the 'revised OECD' scale is used. This uses a weight of 1 for the first adult in the household, 0.5 for subsequent adults and 0.3 for children under the age of 15 years. It should be noted that while equivalence scales play an important role in making such adjustments, they are essentially crude instruments, and the use of different scales may generate different results.

3 The use of the household as the measure of aggregation essentially requires an assumption that resources are pooled within households. While there is some evidence that pooling is far from complete, including differences by gender, there are limited alternatives which can be used in this type of analysis. While traditionally 'income units' have been used in some Australian analysis, this requires an equally or potentially more demanding assumption, that resources are not shared between income units. (Income units represent 'economic units' within families and households, typically separating out the incomes of parents and any dependent children from those of other residents, including older children who are not undertaking full-time study.)

4 While the use of equivalisation has gained wide acceptance in the analysis of income, there is less agreement on how wealth should be analysed. For this reason wealth is shown on an equivalised, per capita and total household basis. 
18. Changes in Inequality in Australia and the Redistributional Impacts of Taxes and Government Benefits

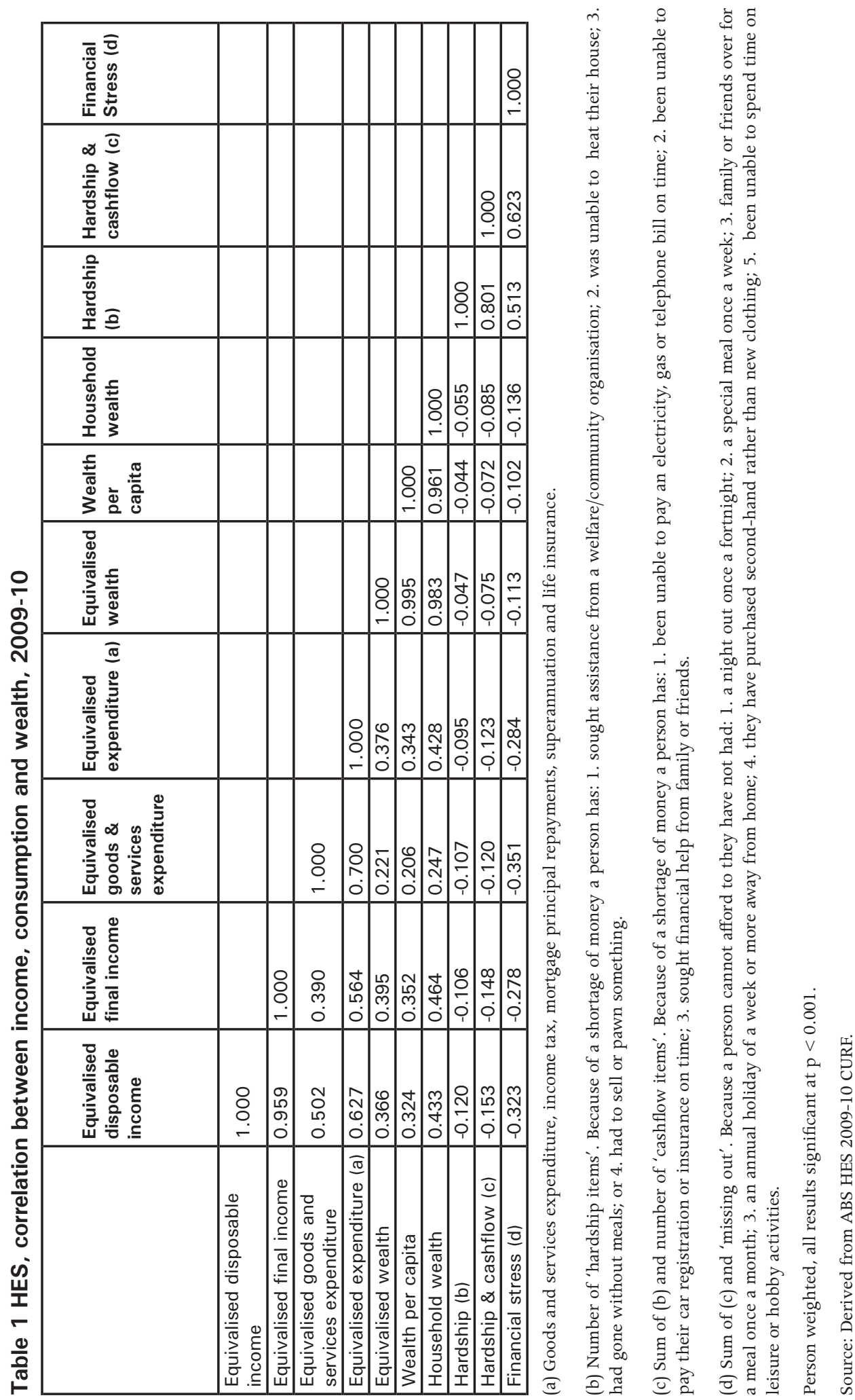


Finally a strong assumption underpinning most inequality analysis is that income is equally valued by all within society and hence it is an appropriate focal point for the analysis. This is an assumption which neither allows for heterogeneity of preferences across the population, including individual tradeoffs between work and leisure, nor potentially, as income is usually treated as being linear, to any diminishing returns on the value of money.

\section{The measurement of income}

Central to the analysis of the distribution of income is the quality of the data collected and made available for analysis. This has two elements of particular import, the quality of the data, and its conceptual basis.

Over recent decades ABS have made considerable efforts to improve their measurement of income, both conceptually, and in collection and processing. Taking this into account, more recent estimates of income may be considered superior to those in earlier surveys. This though has come at the price of comparability over time. ${ }^{5}$ For this reason in some of the analysis of income inequality based on the SIH and the HES multiple measures of income have been constructed to build more compatible time series, or at least provide periods of overlap.

A major conceptual question arising with existing income statistics is the general exclusion of capital gains or the draw down in capital assets. Although seen as a robust strategy under some conceptualisations of income it also has weaknesses. It is inconsistently applied to superannuation where a drawdown of capital as a pension or annuity is treated as income. Similarly while efforts are made to include salary sacrificed superannuation contributions as income, compulsory contributions are not identified. Related to the approach to capital gains is the treatment of apparent losses from investments, including residential property investment and small business operations. In the 2009-2010 SIH, for example, some 8.3 per cent of adults (aged 15 years and over) report having weekly income from residential property. Of these just 30.8 per cent report making a profit, 49.0 per cent report a loss and 20.2 per cent that they break even. Similarly 30.7 per cent of people running their own business report that it makes a loss or just breaks even. Across the adult population as a whole some 5.1 per cent report making a loss on either property, own business or investments. In many cases these recurrent losses are offset by future capital gains.

\footnotetext{
5 Very frequently it is not possible to retrospectively adjust for these. This is for two reasons. The first is the data available in the CURFs, while containing considerable detail especially in some latter surveys, cannot always be disaggregated sufficiently or may simply not have been collected on an appropriate basis. The second is that even modelling of components based on later information may not be possible where the incidence of a practice, for example salary sacrifice, has varied across time and across population subgroups. In this case the situation is further clouded by the fact that there is variation across individual respondents as to whether these amounts had been included in their originally reported levels of income.
} 
With increasing diversity in working patterns a frequently neglected component of income analysis is the costs people incur in earning this income and possibly shifts in the value of home production associated with changes in external employment. Where analysis, such as this, is being conducted over a period of changing patterns of workforce participation, to the extent these are not taken into account, this may well distort some of the findings. Unfortunately few tools exist within the current set of income measures to address these.

\section{What might have affected income inequality in Australia?}

The pattern of income distribution in a society can be affected by many factors. Some of these arise from the operation of labour markets, some from government interventions and others because of the decisions of individuals. These latter can be based on many preferences including the degree to which they wish to trade off income for leisure.

For this paper a number of these are considered below:

- The rates of payment across different occupations, industries and skill levels and the resultant patterns of earnings dispersion;

- Levels of workforce participation, including the impact of involuntary joblessness, and choices about workforce participation, especially within families, and across a person's lifecycle;

- Linked in part to the above, the proportion of economically inactive households, including those drawing down assets;

- Levels of dependence on income support and the rate at which this is paid, both relative to earnings and the relative rates between payments;

- The impact of other government transfers, including support for families; and

- The impact of taxation, in particular its progressivity.

The nature of some of these emphasise the need for caution in the social interpretation of changes in the pattern of income distribution, and in particular concepts such as inequality. For example, an increased level of inequality may arise from an increase in the proportion of partners in couples who participate in the workforce, or from an increase in the number of retirees as a result of demographic change and the degree to which people have built up savings through the superannuation system. 


\section{Earnings}

Over recent decades there has been increasing dispersion of earnings in Australia. Figure 1 shows the trends in the real earnings ${ }^{6}$ of full-time nonmanagerial workers in the period since $1975 .{ }^{7}$ In 2010 this group of workers represented some 89.3 per cent of all full-time employees - with the balance being managerial employees. ${ }^{8}$ Over the whole period the ratio of earnings at the ninetieth percentile relative to the tenth percentile has increased from 2.02 to 2.79 , and relative to median earnings from 1.50 to 1.78 .

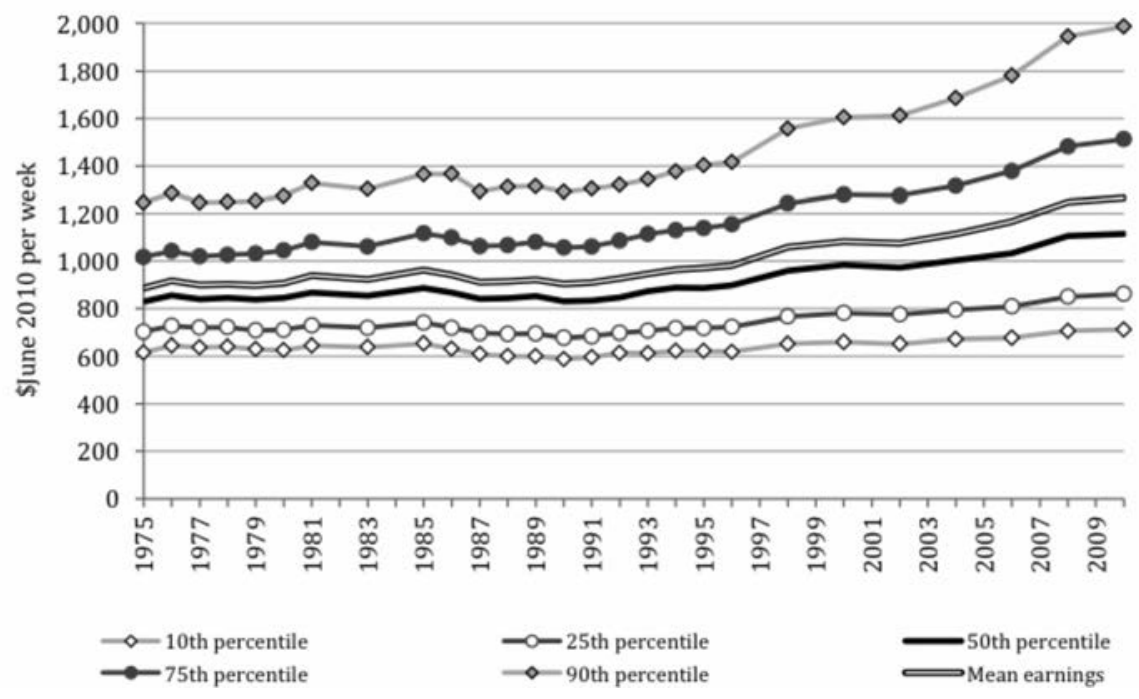

\section{Figure 1 Employee Earnings and Hours Survey, real earnings of full-time non-managerial adult workers at selected percentiles, 1975-2010}

Note: Since May 2006 ABS has ensured that earnings include amounts which are 'salary sacrificed'. This series has smoothed the impact of the introduction of this approach.

Source: ABS EEH Cat No 6306.0 various editions.

6 Income adjusted for changes in prices as measured by the CPI. An issue outside the scope of this paper is the relevance of the expenditure weighted CPI as a measure of price change for population subgroups and other related questions about the methodology of the CPI.

7 This data is from the ABS Employee and Earnings and Hours collection (ABS Cat No 6306.0). This is an employer-based survey with the data being largely taken directly from payroll systems. It can therefore be considered to be less affected by reporting error than that derived from household surveys - such as the similar series which can be extracted from the Survey of Employee Earnings, Benefits and Trade Union Membership (EEBTUM) (ABS Cat No 6310.0).

8 While the omission of this latter group may tend to underestimate the level of higher incomes, the definition of managerial includes supervisory roles with many non-managerial workers being paid at relatively modest levels. Around a third of all managerial employees are paid less than the median earnings of non-managerial employees although 56 per cent are paid above the seventy-fifth percentile. In addition including only fulltime employees may mean that these rates of growth are not wholly reflective of the considerable numbers of persons who are employed part-time. However attempting to develop a series of hourly rates to take this into account is limited by data availability and the accuracy of reported hours of work. 
A second feature of this chart is the extent to which rates of earnings growth have varied over time. Most marked is the limited growth in earnings between the mid 1970s and mid 1990s and strong growth in the period since then, although this latter appears, potentially as a consequence of the Global Financial Crisis (GFC), to have flattened out in the period between 2008 and 2010.

As shown in Table 2, while the real median earnings of these full-time adult non-managerial employees grew at an annualised rate of 0.4 per cent between 1975 and 1996, ${ }^{9}$ the rate of growth rose to 1.6 per cent between 1996 and 2010. For workers at the twenty-fifth percentile of earnings the annualised growth rate of 1.3 per cent between 1996 and 2010 compares with a rate of 0.1 per cent in the preceding period. ${ }^{10}$

Table 2 EEH, Real earnings of full-time non-managerial adult workers at selected percentiles, 1975-1996 and 1996-2010

\begin{tabular}{|c|c|c|c|c|c|c|c|c|}
\hline & 1975 & 1996 & Change & $\begin{array}{c}\text { Annualised } \\
\text { change }\end{array}$ & 1996 & 2010 & Change & $\begin{array}{c}\text { Annualised } \\
\text { change }\end{array}$ \\
\hline & \multicolumn{2}{|c|}{$\$ 2010$} & $\%$ & $\%$ & \multicolumn{2}{|c|}{$\$ 2010$} & $\%$ & $\%$ \\
\hline 10th percentile & 616 & 619 & 0.4 & 0.0 & 619 & 711 & 14.9 & 1.0 \\
\hline 25th percentile & 702 & 722 & 2.8 & 0.1 & 722 & 862 & 19.4 & 1.3 \\
\hline 50th percentile & 829 & 898 & 8.4 & 0.4 & 898 & 1115 & 24.1 & 1.6 \\
\hline 75th percentile & 1018 & 1155 & 13.5 & 0.6 & 1155 & 1513 & 31.0 & 1.9 \\
\hline 90th percentile & 1246 & 1416 & 13.7 & 0.6 & 1416 & 1986 & 40.2 & 2.4 \\
\hline Mean earnings & 887 & 981 & 10.7 & 0.5 & 981 & 1266 & 29.0 & 1.8 \\
\hline $\begin{array}{l}\text { Federal minimum } \\
\text { wage }\end{array}$ & 485 & 502 & 3.4 & 0.2 & 502 & 544 & 8.3 & 0.6 \\
\hline & & & & Ratio & & & & \\
\hline p90/p10 & 2.02 & 2.29 & & & 2.29 & 2.79 & & \\
\hline p90/p50 & 1.50 & 1.58 & & & 1.58 & 1.78 & & \\
\hline p25/p50 & 0.85 & 0.80 & & & 0.80 & 0.77 & & \\
\hline p10/p50 & 0.74 & 0.69 & & & 0.69 & 0.64 & & \\
\hline
\end{tabular}

Source: ABS EEH Cat No 6306.0 various editions.

Many factors underlie these trends, and while these are not explored here they are very relevant to interpreting changes in the distribution of income. For

9 This rate of income growth may however understate the effective remuneration of people over this period. The period also saw a reduction in working hours for many employees from 40 hours per week to 38 and the introduction of superannuation - in particular between 1991 and 2003 when the level of employer contributions increased from three per cent of wages to nine per cent.

10 The growth of earnings recorded over this period in Australia highlights some differences between the Australian and US experience. While real median earnings of full-time non-managerial employees in Australia grew by 34.5 per cent between 1975 and 2010 (31.6 per cent for males and 46.7 per cent for females), in the US the median earnings of male full-time, year-round workers grew by just 2.0 per cent, although that of women grew by 33.4 per cent. (US Census Bureau 2012, Table P-38) 
example, between 2001 and 2011 the proportion of the population aged 15 to 64 years with a bachelor degree or higher qualification increased from 17.0 per cent to 23.7 per cent, and the proportion with any non-school qualification increased from 47.2 per cent to 56.5 per cent. (ABS Cat No 62270DO001_201105, 2011, Table 8.) With such a shift in this aspect of human capital, it is to be anticipated that there would be changes in the distribution of earnings reflecting returns to this investment.

\section{Workforce participation}

Most household income is derived from the participation of household members in the workforce. Hence it would be expected that the distribution of income would be affected if the pattern of participation changes. This section considers two aspects of this participation - employment patterns within households and the impact of retirement and demographic change.

One of the many elements of change in the pattern of employment in Australia in recent decades has been increasing workforce participation by women, and, within couple families, an increase in dual earner couples. Between June 1994 and June 2011, as illustrated in Figure 2, the proportion of couples with a reference person aged 15 to 64 years which had both members engaged in the workforce, rose from 54.4 per cent to 64.4 per cent. Conversely the proportion with a single earner only fell from 32.4 per cent to 26.6 per cent, and with neither member employed from 13.2 per cent to 7.0 per cent. Although many of the second earners in these households only work part-time, and many, especially those with younger children, incur considerable costs in participating in employment, overall this type of shift is likely to increase income polarisation between households, reflecting the different earning capacity of households with zero, one and two employed persons. Amongst couples with children the shift away from the traditional single breadwinner model has been particularly marked. Between 1981 and 2010 the proportion of such families with a single full-time employed person has fallen from 51.4 per cent to 29.5 per cent, while the proportion with two income earners has grown from 40.9 per cent to 60.7 per cent.

Across the income distribution it is a combination of both the rate of pay and the period worked which impacts on household incomes. Table 3 shows the average rate of pay of all employed persons in the household, the average aggregate hours worked by these people and the proportion of households which have such an employed person, by income quintile. 
18. Changes in Inequality in Australia and the Redistributional Impacts of Taxes and Government Benefits

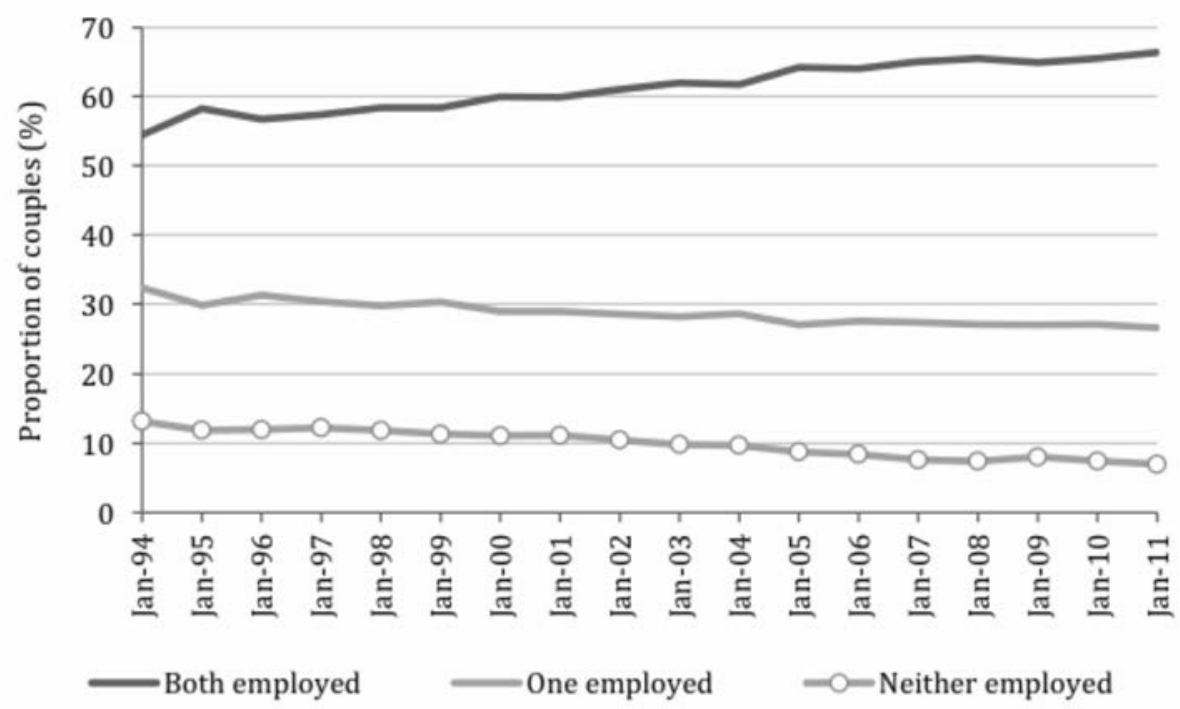

Figure 2 Labour Force Survey, couple households with reference person aged 15-64 years, employment status of couple, 1994-2011

Source: Labour Force Australia, Cat No 6291.0.55.001 Tables ST FA4_aug04 and ST FA4.

Table 3 HES hours worked and rate of pay equivalised household disposable income decile, 2009-10

\begin{tabular}{|l|r|r|r|}
\hline $\begin{array}{l}\text { Equivalised disposable } \\
\text { income quintile }\end{array}$ & $\begin{array}{r}\text { Average hourly wage } \\
\text { of all employed persons } \\
(\mathbf{\$ p h})\end{array}$ & $\begin{array}{r}\text { Hours worked by } \\
\text { employed persons } \\
\text { (Hours) }\end{array}$ & $\begin{array}{r}\text { Proportion with at } \\
\text { least one employed } \\
\text { person (\%) }\end{array}$ \\
\hline 1 & 14.4 & 37.9 & 13.7 \\
\hline 2 & 15.9 & 38.8 & 24.1 \\
\hline 3 & 19.0 & 42.3 & 54.9 \\
\hline 4 & 21.1 & 49.1 & 77.3 \\
\hline 5 & 23.2 & 57.3 & 89.0 \\
\hline 6 & 25.0 & 63.0 & 90.8 \\
\hline 7 & 28.3 & 70.2 & 92.7 \\
\hline 8 & 30.4 & 76.3 & 95.9 \\
\hline 9 & 35.4 & 75.9 & 97.3 \\
\hline 10 & 57.1 & 77.4 & 95.0 \\
\hline
\end{tabular}

Notes: Includes wage and salary and own business income. Population restricted to those households reporting an average hourly earnings rate of $\$ 5$ per hour or more. This leads to some underestimation of the proportion of households with an employed person. 
Relative to the first decile, a household in the fifth decile is 6.5 times more likely to have a person in employment, and if they do, the household receives an average rate of pay, across all employed persons, 62 per cent higher and these people work some 51 per cent more hours. Compared to this household in the fifth decile, a household in the top decile is only 6.7 per cent more likely to have at least one person in employment, and on average works 35 per cent more hours in aggregate, but receives an hourly rate almost 150 per cent higher.

Consideration also needs to be given to the effect of demographic change on workforce participation, in particular the increasing numbers of older, largely retired, households. Between 1976 and 2010 the proportion of households with a reference person aged over 65 years is estimated to have increased by some 24 per cent, rising from some 14.2 per cent of households to 17.6 per cent (see Figure 3).

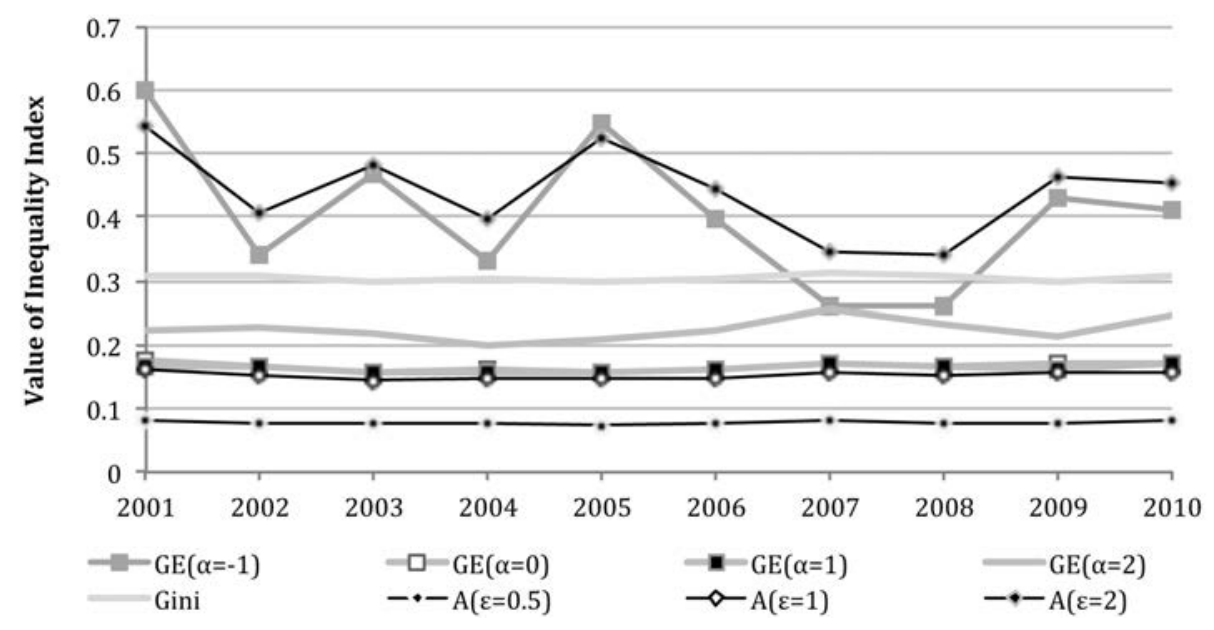

Figure 3 HES, Households with a head aged 65 years and over as a proportion of all households, 1976-2010

Note: Only includes single person and couple only households.

Source: Derived from ABS HES CURFs.

This is a trend which is projected to continue. The 2010 Intergenerational Report (Treasury 2010) suggests that the proportion of the population aged over 65 years will increase from 13.5 per cent in 2010 to 16.4 per cent in 2020 and 22.7 per cent by 2050. More specifically they indicate: As the number of aged people increases, their lower rates of participation are projected to pull down the total labour force participation rate from 65.1 per cent in 2009-10 to 60.6 per cent by 
2049-50.' (ibid: 12) Along with this, it also forecasts a decline in the number of hours worked - in large part because of the higher proportion of the workforce comprised of older workers and women.

Because of their lower levels of income ${ }^{11}$ the growth in the proportion of these households is likely to result in an increase in apparent income inequality. This may be partially offset by the extent to which increasing levels of superannuation savings will see higher incomes amongst many of the households in retirement. Though this may of course increase inequality within this subgroup of households headed by an older person.

As previously noted this increase in the use of superannuation as a source of income may also exacerbate the problems of income measurement.

\section{Income support and other transfers}

Income support and other government transfers play an important role in providing or supplementing the incomes of many Australian households. The extent of these payments can be seen in analysis by the Melbourne Institute on the HILDA survey that reports that in

2008, 36 per cent of persons were living in a household in receipt of income support at the time of interview, and 39 per cent lived in households that had received income support payments at some stage in the preceding financial year.

They note though that 'rates of receipt are somewhat lower among workforceage persons, at 30 per cent for the current week and 34 per cent for the preceding financial year' (Wilkins et al 2011: 41).

11 While a major fall in income with age may have welfare implications - and hence the fact that the elderly tend to have lower incomes can be seen as an issue of concern as it signals a fall in their capacity to consume - and cannot simply be set aside as a consequential effect of demographic change, the case for this is open to some debate. While theory suggests that people will smooth consumption over their lifetime, empirical evidence suggests that consumption tends to decline with age. Furthermore a falling level of current income is often associated with drawing down on savings. This, as discussed earlier, is not consistently recognised in many concepts of income as a measure of economic resources. 


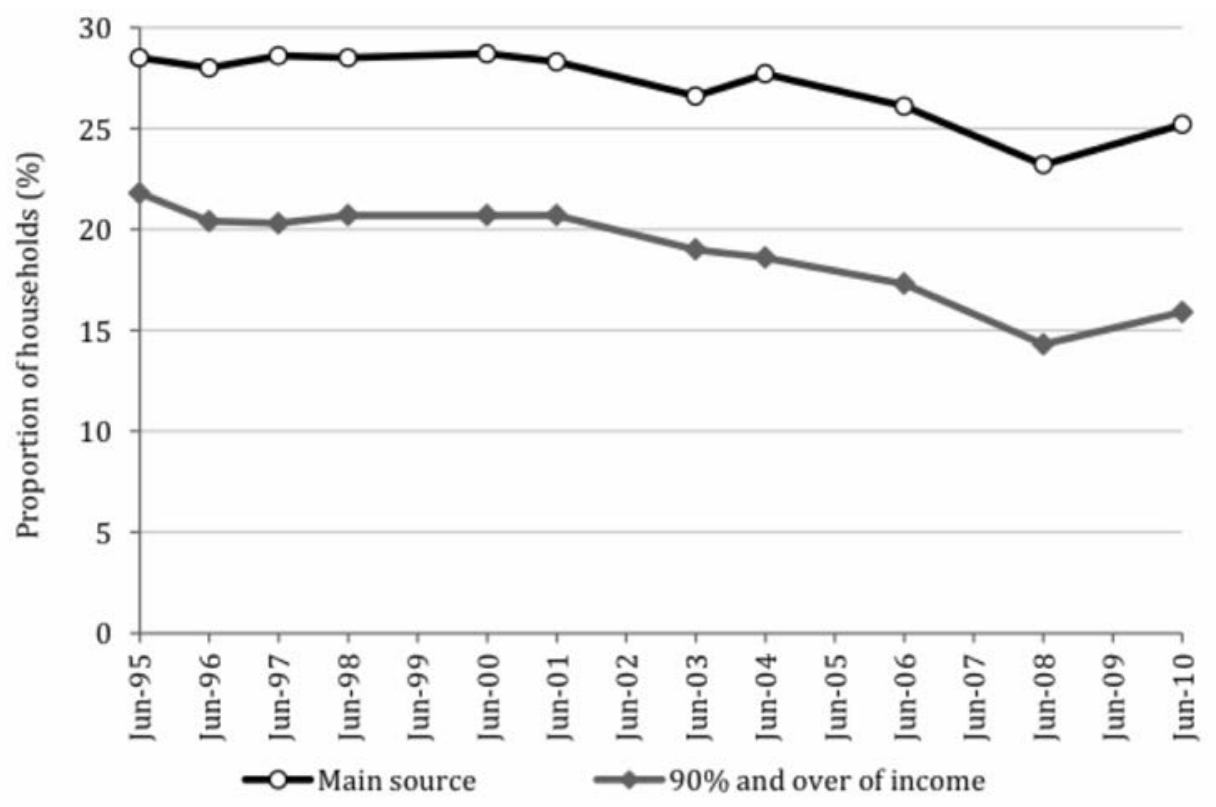

Figure $4 \mathrm{SIH}$, Proportion of households dependent upon government transfers, 1995-2010

Source: ABS (2011) Cat No 65230DO001, Table 3.

The proportion in receipt of this assistance has however not been stable over time. Figure 4, using data from the SIH and a broad definition of transfers which include both income support and family payments, shows the proportion of households which have transfers as their main source of income, and those for which transfers account for 90 per cent or more of their income. While these shares were largely stable for most of the 1990s, since then they have shown a considerable decline. The proportion for households for whom transfers were their main source of income peaked at 28.7 per cent in 2000 before dropping to 23.7 per cent in 2008. The proportion who reported that more than 90 per cent of their income came from transfers fell from a peak of 21.8 in 1995 to 14.3 per cent in 2008. In both cases these proportions then increased a little in 2010 reflecting the impact of the GFC.

All other things being equal, in a system such as Australia's where income support is tightly targeted, it can be anticipated that a decline in the extent of reliance on transfers, which arises because people are no longer eligible to receive an incometested payment, will result in a reduction in the level of inequality.

A second impact of the transfer system on income distribution is the rate at which payments are made, both relative to earnings and within the payments system. 
As shown in Figure 5, a substantial difference has emerged in the rate at which different income support payments are made. This is a result of different approaches to indexation ${ }^{12}$ as well as one-off changes introduced in the 2009-10 budget, which, in particular, impacted on the rate of payment of the pension for single pensioners. ${ }^{13}$

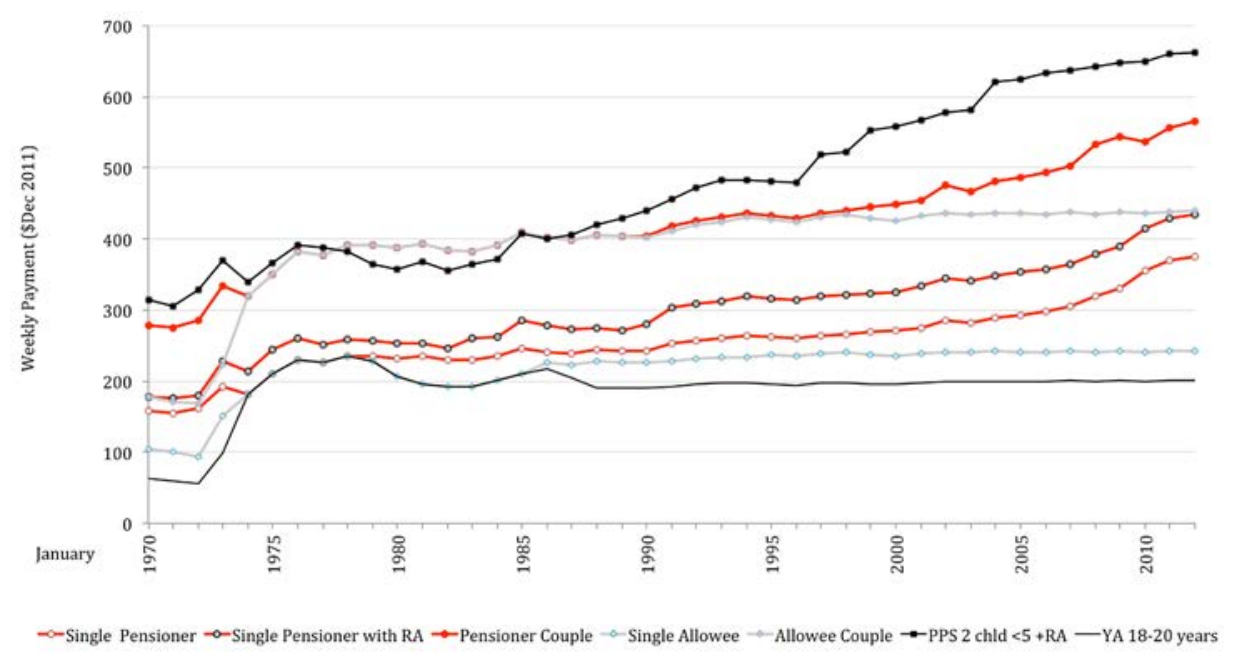

\section{Figure 5 Real weekly rates of payment, selected income support payments, $1970-2012$}

Source: FaHCSIA 2012, Section 5.2 and other administrative collections.

These differential rates of payment, especially when compared with the situation in the late 1970s when all payments were made at a common rate and even much of the 1990s when the differences between the payment rates were relatively small, are likely to be reflected in increasing income inequality.

A further impact of transfer payments concerns the provision of support for families. The level of support provided to families with children has also grown over time, as well as being extended to many households in the workforce. This not only impacts directly on the income distribution, but also the relative outcomes for those with and without children.

12 Since the 1980s, while allowance type payments such as Newstart and Youth Allowance have been adjusted for price changes only, pensions are adjusted to maintain a relativity with earnings as well as providing protection against changes in prices.

13 The pension rate shown in the table includes the value of bonuses paid to Older Australians/Seniors in 2001, 2006, 2007 and 2008, but excludes the 2008 Economic Security Bonus Payment, as this formed part of a much wider payment. 


\section{Income tax}

The second major intervention by government which impacts on the distribution of disposable income is income tax.

Traditionally most income tax systems have been progressive with higher tax rates being levied against those with higher incomes. This approach reflects both an assessment of the relative capacity of individuals to pay tax, and explicit redistributive goals. Since 1999-2000 as illustrated in Figure 6, there have been substantial changes in the rates at which income tax is levied at particular income levels. Particularly marked are the changes in 2000-01 and again in 2006-07. While a simple chart such as this does not illustrate the full range of changes including changes to taxation offsets, shifts between the use of tax and the transfer system to deliver assistance, or trade-offs between direct and indirect tax (in particular the introduction of the GST in July 2000), it nevertheless shows how thresholds have moved and the effective marginal tax rates have reduced over wide bands of income.

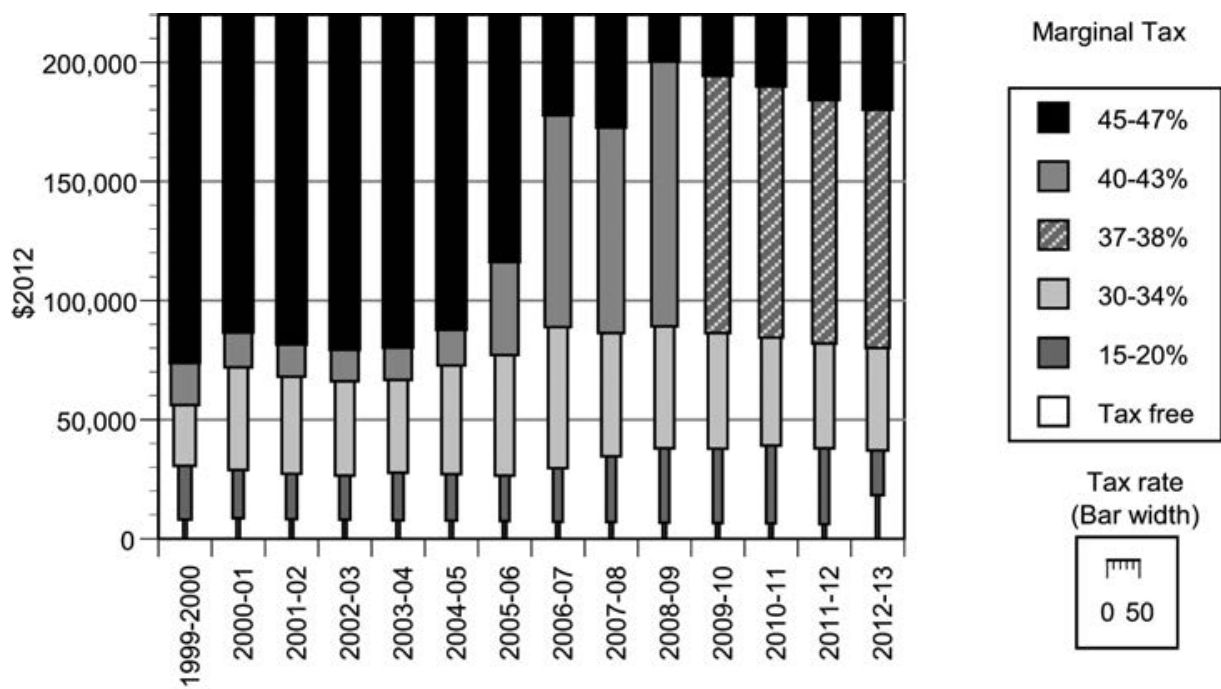

Figure 6 Income tax scales, $1999-2000$ to $2012-2013$

Note: Bar width indicates relative tax rate.

Source: ATO (2012a, b).

The cumulative impact of the changes between 2000-01 (that is, just after the specific changes introduced along with the GST) and 2009-10, along with changes in the distribution of income amongst taxpayers, ${ }^{14}$ are shown in Table 4.

14 The population of taxpayers varies as a proportion of the total population depending not just on the income of individuals - that is, low income individuals are excluded from the data - but also by changes in the real value of the minimum tax threshold. Where the threshold is held flat in nominal terms - as it has over a 
As this shows, the actual pattern in changes in the average rates of taxation at different points of the distribution is complex. For the bottom vingtile the average rate of taxation fell by 1.18 percentage points, the amount of reduction then increased up to the seventh income vingtile where it peaked at 3.94 percentage points - a reduction in the average tax rate paid from 15.4 per cent to 11.4 per cent. The rate of reduction then declined reaching a low in the sixteenth vingtile at 0.93 percentage points. After this the rate of decline again commenced to increase until it reached a reduction in the average rate of income tax paid of 2.25 percentage points for the five per cent of taxpayers with the highest incomes.

Also noticeable in the table are changes in the income share received at various points in the distribution. In particular, the share of total income received by the top five per cent of taxpayers increased from 19.8 per cent in 2000-01 to 20.5 per cent in 2009-10. Despite the fall in their average tax rate over the period the share of taxation they paid increased from 31.3 per cent to 33.5 per cent.

Table 4 Income tax, average rates of taxation and shares of income and tax by total income vingtile, 2000-01 and 2009-10

\begin{tabular}{|c|c|c|c|c|c|c|c|c|c|c|}
\hline \multirow{2}{*}{$\begin{array}{l}\text { Vingtile } \\
\text { of } \\
\text { taxpayer }\end{array}$} & \multicolumn{2}{|c|}{ Total income } & \multicolumn{2}{|c|}{ Income Tax Payable } & \multicolumn{2}{|c|}{ Share of income } & \multicolumn{2}{|c|}{ Share of tax } & \multicolumn{2}{|c|}{ Average tax rate } \\
\hline & $\begin{array}{l}2000- \\
2001\end{array}$ & $\begin{array}{c}2009- \\
10\end{array}$ & $\begin{array}{l}2000- \\
2001\end{array}$ & $\begin{array}{c}2009- \\
10\end{array}$ & $\begin{array}{c}2000- \\
2001\end{array}$ & $\begin{array}{c}2009- \\
10\end{array}$ & $\begin{array}{c}2000- \\
2001\end{array}$ & $\begin{array}{r}2009- \\
10\end{array}$ & $\begin{array}{l}2000- \\
2001\end{array}$ & $\begin{array}{c}2009- \\
10\end{array}$ \\
\hline \multicolumn{5}{|c|}{$\$ m$} & \multicolumn{6}{|c|}{$\%$} \\
\hline 1 & $3,489.0$ & $7,976.9$ & 118.0 & 175.9 & 1.0 & 1.4 & 0.2 & 0.1 & 3.4 & 2.2 \\
\hline 2 & $4,902.0$ & $10,028.3$ & 273.0 & 399.7 & 1.5 & 1.7 & 0.4 & 0.3 & 5.6 & 4.0 \\
\hline 3 & $6,101.0$ & $11,681.7$ & 481.0 & 690.4 & 1.8 & 2.0 & 0.6 & 0.6 & 7.9 & 5.9 \\
\hline 4 & $7,274.0$ & $13,286.9$ & 700.0 & 900.8 & 2.2 & 2.3 & 0.9 & 0.7 & 9.6 & 6.8 \\
\hline 5 & $8,368.0$ & $14,724.9$ & 875.0 & $1,082.3$ & 2.5 & 2.6 & 1.1 & 0.9 & 10.5 & 7.4 \\
\hline 6 & $9,359.0$ & $16,052.3$ & $1,071.0$ & $1,348.1$ & 2.8 & 2.8 & 1.4 & 1.1 & 11.4 & 8.4 \\
\hline 7 & $10,305.0$ & $17,314.9$ & $1,399.0$ & $1,674.2$ & 3.1 & 3.0 & 1.8 & 1.4 & 13.6 & 9.7 \\
\hline 8 & $11,249.0$ & $18,549.4$ & $1,728.0$ & $2,118.1$ & 3.3 & 3.2 & 2.2 & 1.8 & 15.4 & 11.4 \\
\hline 9 & $12,178.0$ & $19,932.1$ & $2,032.0$ & $2,598.6$ & 3.6 & 3.5 & 2.6 & 2.2 & 16.7 & 13.0 \\
\hline 10 & $13,142.0$ & $21,417.9$ & 2,338.0 & $3,106.3$ & 3.9 & 3.7 & 3.0 & 2.6 & 17.8 & 14.5 \\
\hline 11 & $14,159.0$ & $23,038.1$ & $2,654.0$ & $3,663.4$ & 4.2 & 4.0 & 3.4 & 3.0 & 18.7 & 15.9 \\
\hline 12 & $15,248.0$ & $24,833.5$ & 2,989.0 & $4,271.9$ & 4.5 & 4.3 & 3.8 & 3.6 & 19.6 & 17.2 \\
\hline 13 & $16,446.0$ & $26,811.6$ & $3,353.0$ & $4,952.4$ & 4.9 & 4.7 & 4.3 & 4.1 & 20.4 & 18.5 \\
\hline 14 & $17,760.0$ & $29,025.2$ & $3,753.0$ & $5,713.1$ & 5.3 & 5.1 & 4.8 & 4.7 & 21.1 & 19.7 \\
\hline 15 & $19,296.0$ & $31,638.9$ & $4,210.0$ & $6,553.8$ & 5.7 & 5.5 & 5.4 & 5.4 & 21.8 & 20.7 \\
\hline 16 & $21,080.0$ & $34,699.4$ & $4,743.0$ & $7,483.5$ & 6.3 & 6.0 & 6.1 & 6.2 & 22.5 & 21.6 \\
\hline
\end{tabular}

substantial period - more low-income earners may become liable to pay tax even if their income has remained flat over time. This in itself will result in an apparent concentration of earnings at the top of the population. Over short time frames this effect is likely to be negligible. 
Measuring and Promoting Wellbeing: How Important is Economic Growth?

\begin{tabular}{|c|c|c|c|c|c|c|c|c|c|c|}
\hline \multirow{2}{*}{$\begin{array}{c}\text { Vingtile } \\
\text { of } \\
\text { taxpayer }\end{array}$} & \multicolumn{2}{|c|}{ Total income } & \multicolumn{2}{|c|}{ Income Tax Payable } & \multicolumn{2}{|c|}{ Share of income } & \multicolumn{2}{|c|}{ Share of tax } & \multicolumn{2}{|c|}{ Average tax rate } \\
\hline & $\begin{array}{l}2000- \\
2001\end{array}$ & $\begin{array}{c}2009- \\
10\end{array}$ & $\begin{array}{l}2000- \\
2001\end{array}$ & $\begin{array}{c}2009- \\
10\end{array}$ & \begin{tabular}{|l|}
$2000-$ \\
2001
\end{tabular} & $\begin{array}{c}2009- \\
10\end{array}$ & \begin{tabular}{|l|}
$2000-$ \\
2001
\end{tabular} & $\begin{array}{r}2009 \\
10\end{array}$ & \begin{tabular}{|l|}
$2000-$ \\
2001
\end{tabular} & $\begin{array}{c}2009- \\
10\end{array}$ \\
\hline 17 & $22,947.0$ & $38,298.3$ & $5,421.0$ & $8,581.6$ & 6.8 & 6.7 & 7.0 & 7.1 & 23.6 & 22.4 \\
\hline 18 & $25,801.0$ & $43,351.0$ & $6,574.0$ & $10,465.9$ & 7.7 & 7.6 & 8.4 & 8.7 & 25.5 & 24.1 \\
\hline 19 & $30,974.0$ & $53,515.3$ & $8,822.0$ & $14,230.7$ & 9.2 & 9.3 & 11.3 & 11.8 & 28.5 & 26.6 \\
\hline 20 & $66,655.0$ & $117,523.6$ & $24,365.0$ & $40,315.6$ & 19.8 & 20.5 & 31.3 & 33.5 & 36.6 & 34.3 \\
\hline Total & $336,733.0$ & $573,700.1$ & \begin{tabular}{|l|}
$77,899.0$ \\
\end{tabular} & \begin{tabular}{|l|}
$120,326.4$ \\
\end{tabular} & 100.0 & 100.0 & 100.0 & 100.0 & 23.1 & 21.0 \\
\hline
\end{tabular}

Source: Australian Taxation Office (2012 c) Table 9; Australian Taxation Office (2003) Table 9.

The complex pattern of these changes also makes it difficult to simply interpret the overall impact. On balance, at least at this level of aggregation the overall impact on rates is to increase relative progressivity. However, changes in progressivity across taxpayers, associated with lower average tax rates and potentially increasing earnings dispersion, does not necessarily mean that the tax system has been more redistributive across the population as a whole.

\section{Trends in inequality}

As seen above there are many reasons to expect that the pattern of income distribution has changed over recent decades. While some of these may be considered to be enhancing equality, on balance they appear to be more inclined towards an increase in inequality. This section examines the major data series introduced earlier to identify the degree to which there have been changes in the distribution of income in Australia, in particular over the past decade, but more generally since the 1970s. The focus as discussed previously is on equivalised disposable income inequality and the Gini is used as the main measure. This section considers in turn the results gained from analysis of the three major data collections identified above, the SIH, HES and HILDA. While the analysis of the SIH and HES mainly use current income, in some selected tables, and in the analysis of HILDA, annual data is used.

\section{Measures of inequality}

For the most part this paper uses the Gini coefficient as the main measure of inequality. The case for this approach is however not clear-cut.

On one hand the measure is:

- The most commonly used measure and as such is familiar to most users; 
- Has a relatively simple statistical basis and links to the Lorenz curve (as it is essentially the area between the line of uniform distribution and the Lorenz curve of the income distribution, expressed as a proportion of the area under the line);

- Able to handle zero and negative values of income;

- Relatively easy to decompose, in particular with regard to income source.

On the other hand, it lacks the deliberate construction of the Atkinson and Generalised Entropy measures which demand a choice of parameter to reflect the value attached to specific forms of inequality. Also, in common with other single value measures, because of the myriad ways in which inequality can arise at different points of the distribution, it is not necessarily, by itself, fully informative of changes in inequality. ${ }^{15}$ As with other single measures there is also no normative basis for interpreting any particular level of the measure. That is, while it is generally recognised that extremes of inequality, or for that matter equality, may be associated with adverse outcomes, there is no particular basis for considering what an 'appropriate' level might be. Because of this there is a frequent tendency to assess all shifts towards a higher level of inequality as being negative, and any drops as being a positive.

\section{$\mathrm{SIH}$}

For the purposes of this analysis, data since 1990 has been used. Over the period to 2009-10 twelve surveys have been undertaken. These however have used a number of different income definitions. While the ABS has published consolidated series of key statistics including the Gini coefficient for the current income measure for the period since 1994-95, they caution

Estimates presented for 2007-08 and 2009-10 are not directly comparable with estimates for previous cycles due to the improvements made to measuring income introduced in the 2007-08 cycle. Estimates for 200304 and 2005-06 have been recompiled to reflect the new treatments of income, however not all new components introduced in 2007-08 are available for earlier cycles (ABS 2011, Cat No 6523.0: 11).

15 A distribution can be unequal in many different ways. For example, it may be unequal because those at the bottom of the distribution have very little, while the balance of the population has higher but relatively evenly distributed incomes. Alternatively it can arise because most of the population has relatively similar incomes and a small subgroup has very substantially higher incomes. Although the subtleties of these distributions can be presented in graphic forms - such as Lorenz curves which plot the cumulative distribution of ranked income across the population, they cannot be seen in a single value measure. 
As seen in Figure 7, which includes estimates derived from the CURFs using a series of different definitions, this is clearly the case and indeed the ABS series seeks to link the series rather than provide a more substantive common definition.

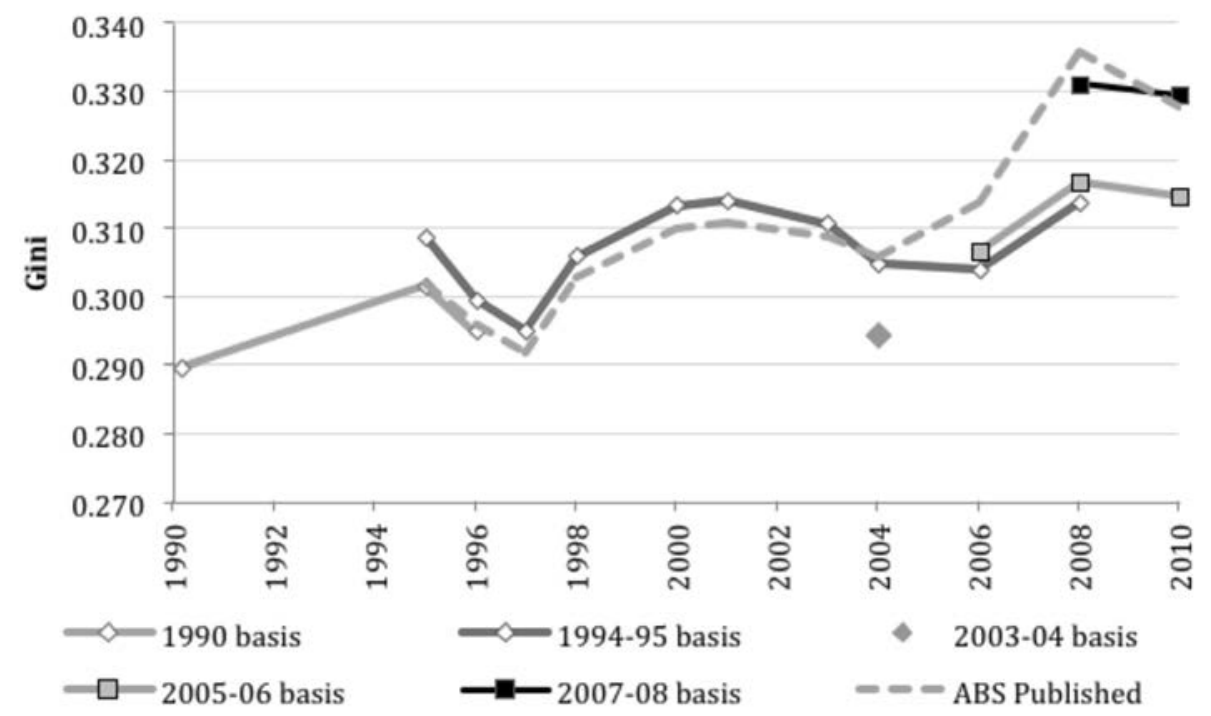

Figure $7 \mathrm{SIH}$, Current equivalised disposable income, estimated Gini, using different income definitions, 1990-2010

Note: Data plotted at the end of each financial year in which the survey was conducted.

Source: Derived from ABS SIH CURFs and ABS 2011, Cat No 6523.0.

Given the apparent close overlaps between the definitions using the 1990, 199495 and 2005-06 bases over the period when data is available or can be derived under multiple income definitions, it is reasonable to consider a composite of these to be more indicative of trends over time. This would suggest that inequality of current equivalised disposable income, as measured by the Gini, rose from around 0.290 in 1990 to a peak of around 0.314 in 2000-01 before declining to a low of 0.304 in 2005-06. After this point it increased again to reach a level of 0.317 and 0.315 in 2007-08 and 2009-10 respectively.

The pattern shown in the annual data from the SIH (Figure 8) is somewhat different - suggesting a slow but consistent rise between 1998-99 to 2002-03, from a Gini of 0.296 to 0.310 , before accelerating rapidly to reach a Gini of 0.345 in 2006-07 with a slight decline to 0.305 in 2008-09. ${ }^{16}$

16 An unusual feature of the distribution of this annual income relative to the distribution of current income is the identification of higher inequality in the distribution of annual income. Intuitively it could be 
18. Changes in Inequality in Australia and the Redistributional Impacts of Taxes and Government Benefits

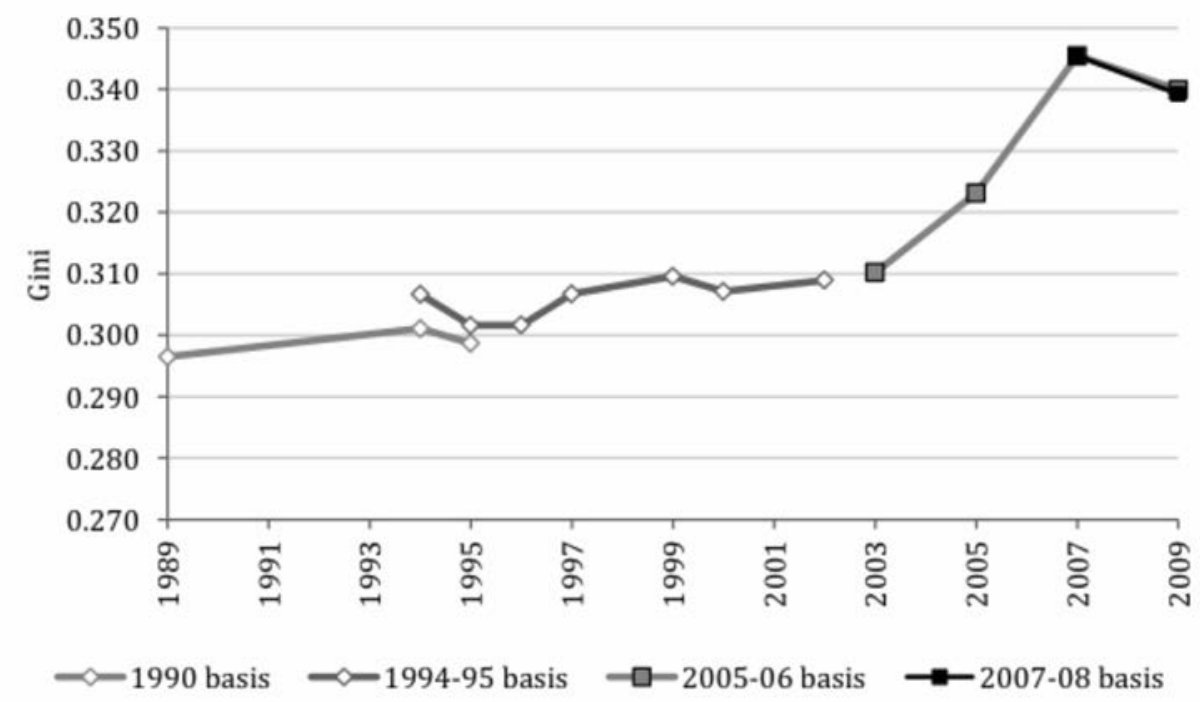

Figure 8, SIH, Annual equivalised disposable income, estimated Gini, using different income definitions, 1989-1990 to 2008-09

Note: Data plotted at the end of each of the financial years for which it was collected.

Source: Derived from ABS SIH CURFs.

The underlying trends in real current equivalised income, as measured in terms of the average income per decile are shown in Figure 9. This repeats the earlier pattern of limited if any income growth until the mid 1990s then steady increases for most groups to the early 2000s followed by rapid growth until 2007-08, after which they tended to be steady or decline.

The chart also shows the marked differences in income growth over the period. While the income of the top decile increased by 73.6 per cent over the whole period, that of the lowest decile increased by just under half this, 32.4 per cent. Although there was some dispersion at almost all points of the income distribution, most apparent has been the way in which the income growth of the top ten per cent of the population has far exceeded that of all other groups. The pattern of growth of this one decile is also very similar to the pattern of change in the Gini coefficient across the period.

expected that over a longer period of time there would be greater income smoothing and hence a lower level of inequality. As seen in later data from HILDA where income is smoothed over a number of years, the level of measured inequality drops. 


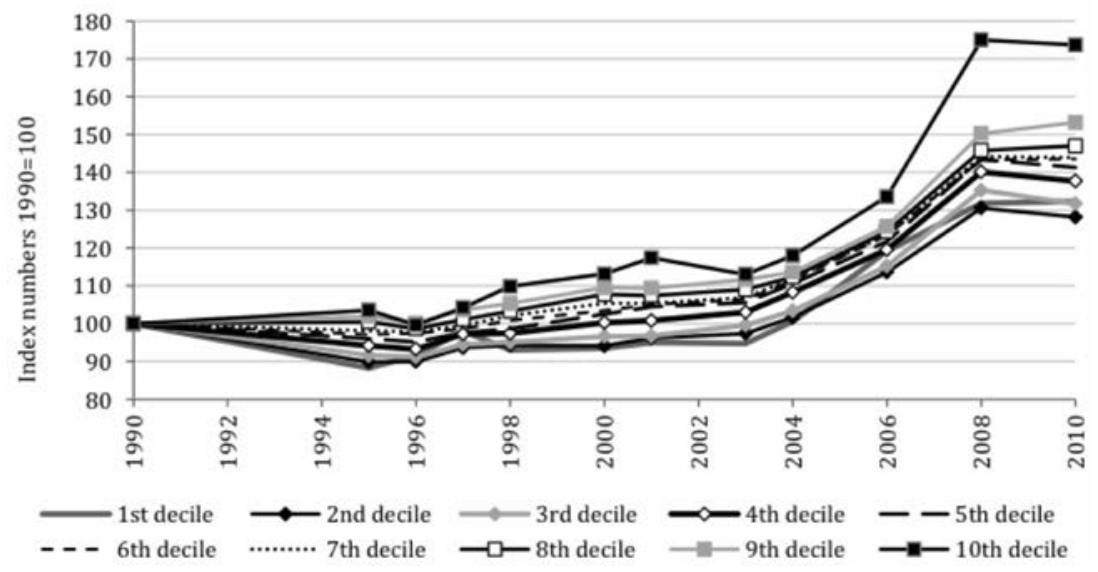

Figure $9 \mathrm{SIH}$, Mean real equivalised disposable current income by income decile, index numbers, 1990 to 2009-10

Source: Derived from ABS SIH CURFs.

\section{HES}

As with the SIH, deriving a long time series from the HES is not straightforward. In addition to changes in definitions of income and whether or not tax data was collected or imputed, a particular problem is caused by the relative treatment of negative incomes. As discussed earlier, the data from the HES has been subject to some edits to seek to derive a more consistent series.

Figure 10 shows the results of a number of different treatments of those households with zero or negative incomes, either in aggregate or for some income components. These include: setting all negative incomes to zero, setting the contribution of own business and investment to zero where the combined total is negative; bottom coding all records below the fifth percentile to the fifth percentile value, and simply excluding records with negative and zero values. In all cases these treatments have been applied to the series which has been adjusted to maximise comparability over time.

As illustrated, the approaches can make a considerable difference in the value of the point estimates of the Gini coefficient. This is particularly marked in the 1993-94 HES, with the smallest differences showing in 2009-10. 
18. Changes in Inequality in Australia and the Redistributional Impacts of Taxes and Government Benefits

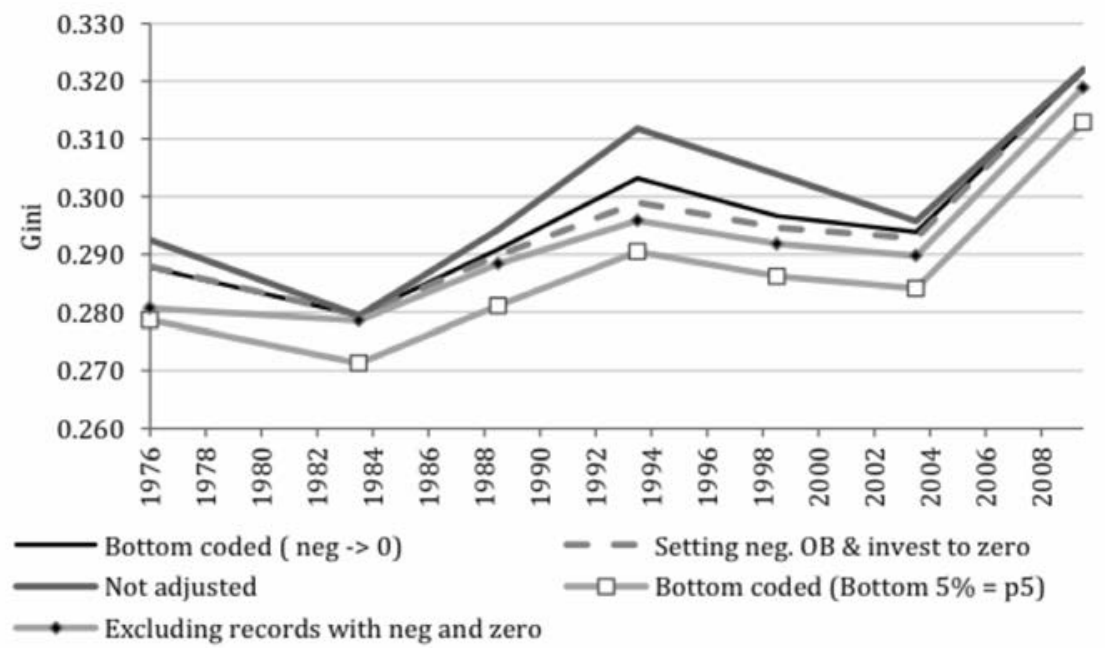

Figure 10 HES, Current equivalised disposable income, estimated Gini, using different income treatments, 1976-2010

Note: $\mathrm{OB}=$ Own Business.

Source: Derived from ABS HES CURFs.

Notwithstanding these differences, all of the series show a similar pattern, although differing in the magnitude of the change. This pattern comprises: a fall in inequality as measured by the Gini between 1976 and 1984; before rising to a peak in 1993-94; declining until 2003-04; and then increasing sharply to 200809. The overall shift in the Gini ranged from an estimated increase of 0.030, from 0.293 and 0.322 in the 'non-adjusted' series, to 0.038 in the series which excluded negative and zero incomes - an increase from 0.281 to 0.319 .

The HES also allows one to consider changes in consumption inequality. Because the definition of consumption in 1976 included the principal component of home loan repayments for owner occupied housing, direct comparisons on current definitions cannot be made consistently across the period. Figure 11 plots the trend in the Gini coefficient using three different treatments of housing costs.

When compared with the income-based estimates, these data suggest a similar decline in inequality between 1976 and 1984, much slower growth until 200304, without the pronounced peak in 1994, and then a strong increase to 200910, although this last movement was less than half the growth in the income measures. The increase in the Gini coefficient over this period was much less than that recorded for income - ranging from 0.007 where all housing costs are excluded to 0.014 where all housing capital repayments are included in the measure of consumption. These are quite modest changes. 


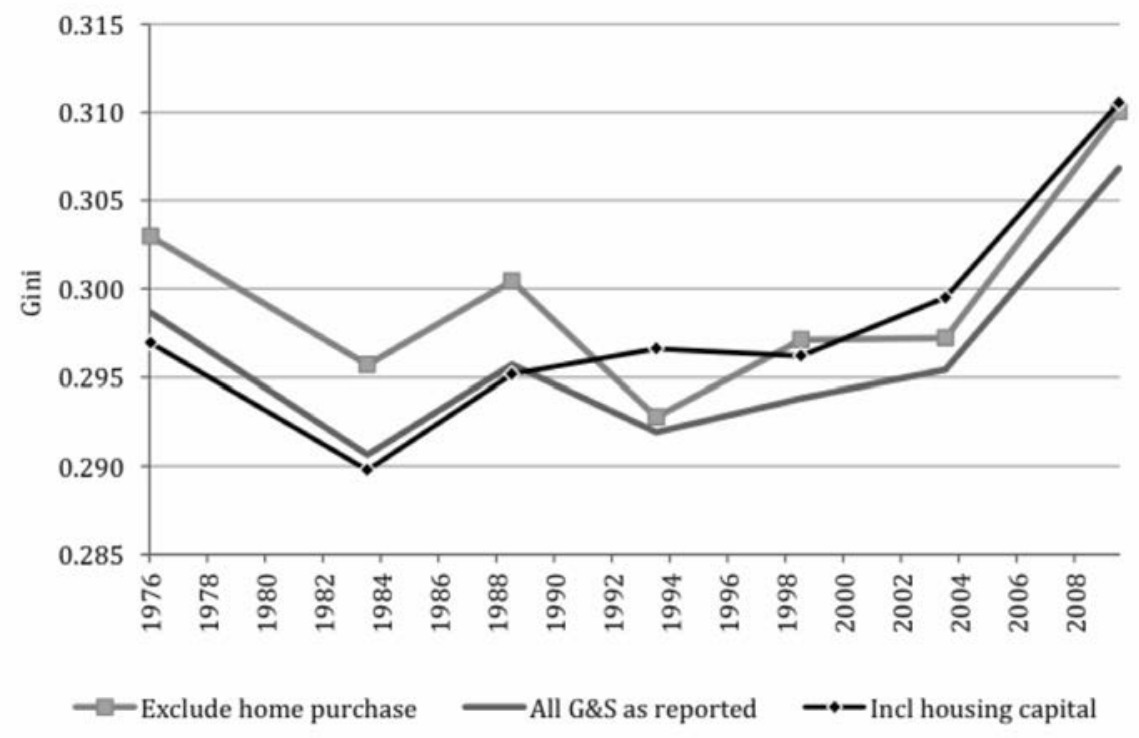

Figure 11 HES, Equivalised consumption, Gini, using different treatments of home purchase costs, 1976-2010

Source: Derived from ABS HES CURFs.

The pattern of income growth underlying these HES results is shown in Figure 12. As with the data from the SIH, this points to a concentration of income growth in the second half of the period (and indeed negative results for all but the second vingtile between 1976 and 1994), and much stronger growth for those households with the highest five per cent of incomes. ${ }^{17,18}$

17 It is noted that, as these surveys are cross-sectional, these rates of growth are based on comparing those households at a particular point in the income distribution in the first period with the set of potentially different households at that point in the second period. No information is available on whether or not these households are common across surveys. This latter style of analysis requires the use of longitudinal data.

18 Notwithstanding the specific impact of the growth in these higher incomes on income distribution, analysis suggests that even if households in the top vingtile of income are excluded, the trends in inequality presented earlier persist. 


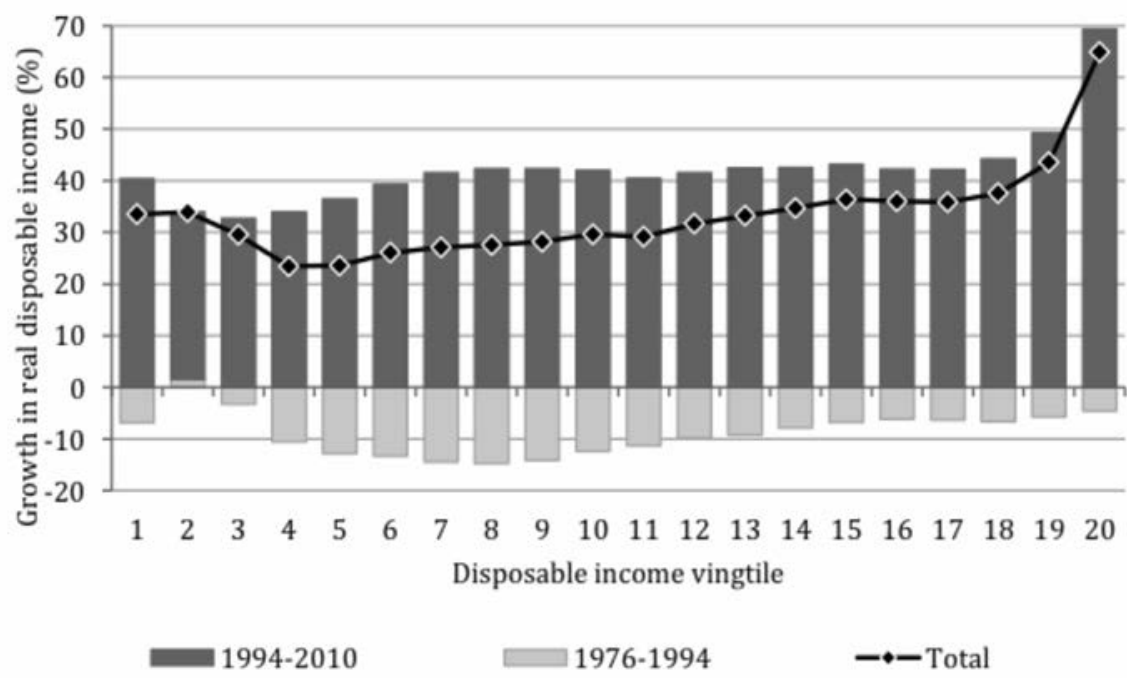

Figure 12 HES, Growth in equivalised real household disposable income, 1976-2010

Source: Derived from ABS HES CURFs, 1976, 1993-94 and 2009-10.

The distribution of equivalised disposable income, in the form of Lorenz curves is plotted in Figure 13 for 1976, 1999 and 2000.

Visually this provides an impression that between each of these three time periods inequality increased, as shown by the consecutive Lorenz curves moving to the right and further away from the line of equality (the diagonal line). More detailed analysis, using percentile points of the distribution, suggests that this is not the case between 1976 and 1999 as the two lines cross. Indeed up to the seventeenth percentile the 1976 line is dominated by the 1999 line, with this again occurring from the ninety-seventh percentile onwards. This reflects the phenomena seen in the earlier chart of income growth of smaller falls in income for these groups, and indeed the slight gain for the second vingtile, relative to the middle. 


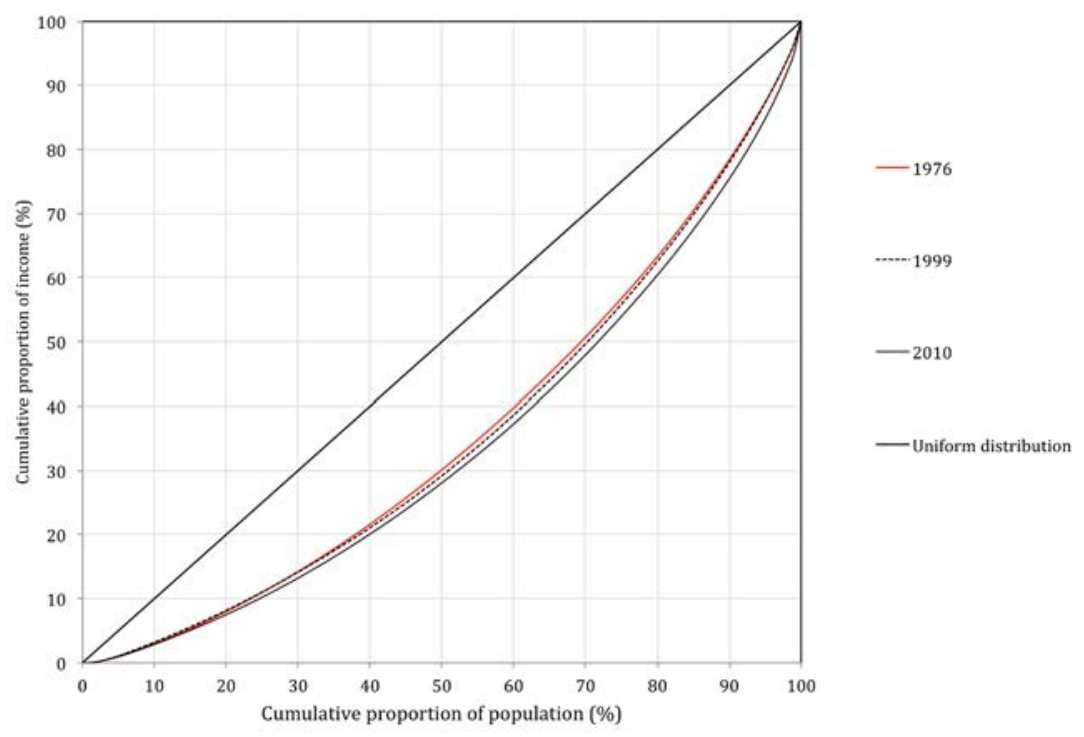

Figure 13 HES, Equivalised disposable income, Lorenz curves, 1976, 1999 and 2010

Source: Derived from ABS HES CURFs, 1976, 1998-99 and 2009-10.

In the case of the comparison between 1999 and 2010, with the exception of the first two percentile points, the 1999 distribution dominates. Given the extent to which these very low incomes are more likely to be strongly affected by how various income losses are treated, there are strong grounds to suggest that dominance has been established and hence income in 2010 was unequivocally less equally distributed.

This finding though is only a partial insight into the possible changes in welfare over this period. As was seen above, the period since 1999 was also marked by strong income growth. The effect of this can be seen in the Generalised Lorenz Curves, Figure 14. 
18. Changes in Inequality in Australia and the Redistributional Impacts of Taxes and Government Benefits

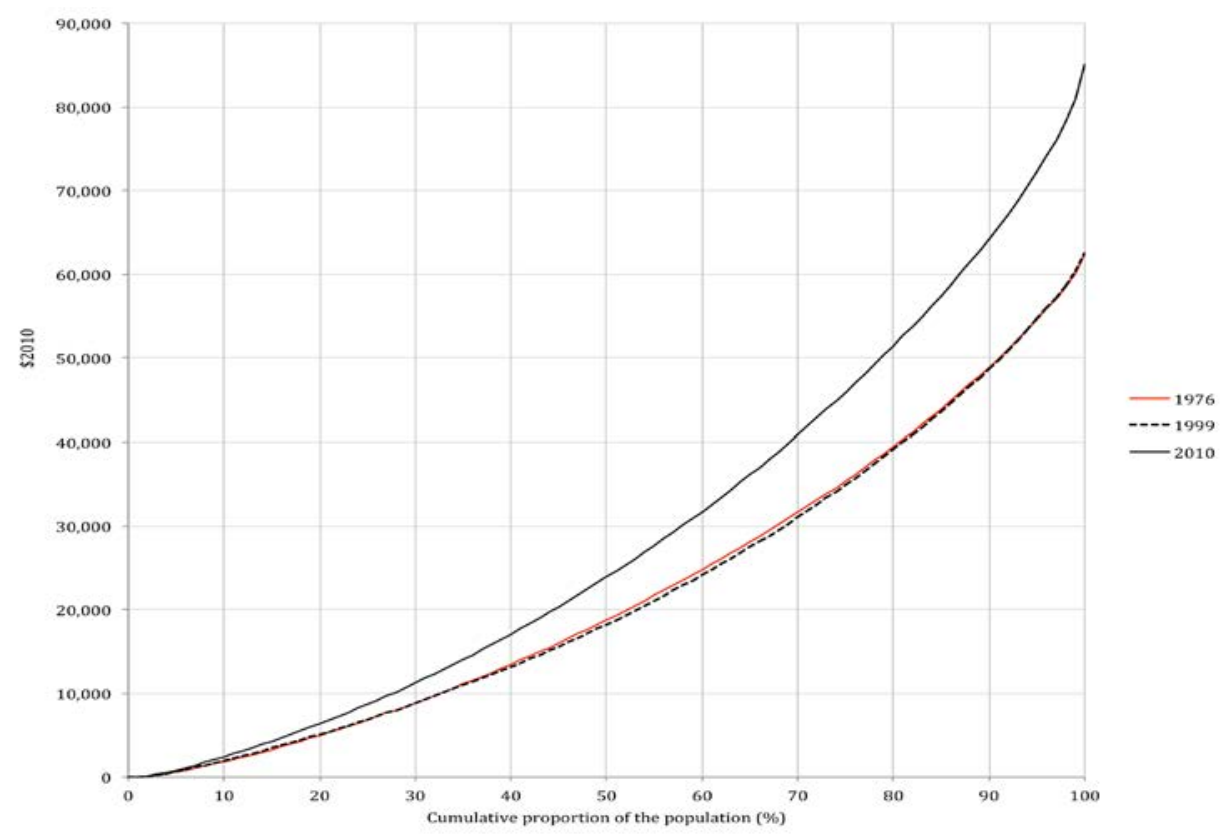

Figure 14 Equivalised disposable income, generalised Lorenz curves, 1976, 1999 and 2010

Source: Derived from ABS HES CURFs 1976, 1998-99 and 2009-10.

In this it is clear that the 2010 distribution clearly dominates those of the previous years, that is, there were gains in income by the population across the income distribution.

\section{HILDA}

The HILDA dataset varies from the ABS series in a number of ways. The most prominent of these is its longitudinal basis, a characteristic which will be considered later in this section. A further feature is that unlike the other datasets discussed here, the HILDA dataset is subject to revision over time. In particular as additional information is obtained from subsequent waves of the survey, it is possible to improve on the imputation of missing values in earlier waves. A consequence, from the perspective of analysis, is that estimation of particular population parameters can vary depending upon the specific release of HILDA used. This, as is illustrated in Figure 15, is the case with estimates of the inequality of the income distribution.

While there is considerable fluctuation in the Gini coefficient between the series and over time, there appear to be no strong or consistent time trends. The main HILDA Wave 10.0 file result indicates that in 2010 the Gini at 0.314 was virtually 
the same as the 0.315 in 2001 . Using the series with zero and negative disposable incomes excluded, the value of the Gini coefficient at both the beginning and end was 0.308 .

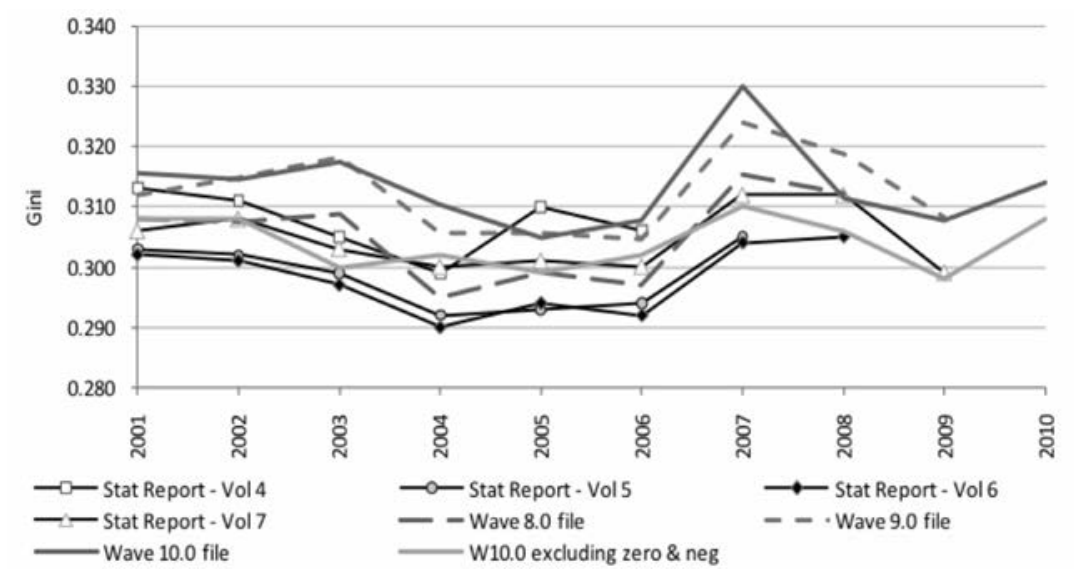

\section{Figure 15 HILDA, Equivalised disposable income, Gini, various sources}

Source: Derived from HILDA, Wave 8.0, 9.0 and 10,0 c files, Wilkins et al 2009, 2010 and 2011.

The Gini is though not the only instrument for measuring inequality and changes in inequality over time. Figure 16 and Figure 17 present estimates derived from a number of different methodologies, firstly income ratios at different points in the income distribution, and secondly the Atkinson and General Entropy/Theil measures. For these charts records with negative and zero incomes have been excluded as a number of these measures cannot deal with these values and are sensitive to the value which is substituted. ${ }^{19}$

Looking at the income ratios, changes are on the whole slight, although some particular patterns show through. In the case of the p75:p25 ratio, that is the income of a person at the seventy-fifth percentile of the income distribution relative to a person at the twenty-fifth percentile, the ratio fell from being above 2.1 in each of the first five waves of the survey to below in the second five waves. Overall it fell from 2.13 to 2.08 - a 2.4 per cent change. There were also falls in the p75:p50 ratio ( -2.2 per cent), the p90:p50 ratio ( -2.0 per cent) and the p90:p10 ratio ( -1.6 per cent). These figures are surprising in that this data does not appear to reflect the much stronger income growth at the top of the income distribution seen in the other series over the 2000s. This is potentially

19 The sensitivity of measures to the use of substitute values for observations with negative or zero values is discussed in Appendix 3 to the User Guide to the 2009-10 HES and SIH (ABS Cat NO 6503.02012 ). 
a consequence of the growth being most concentrated in the very top of the income distribution and hence not impacting as much on the actual cut-off point for the top vingtile.

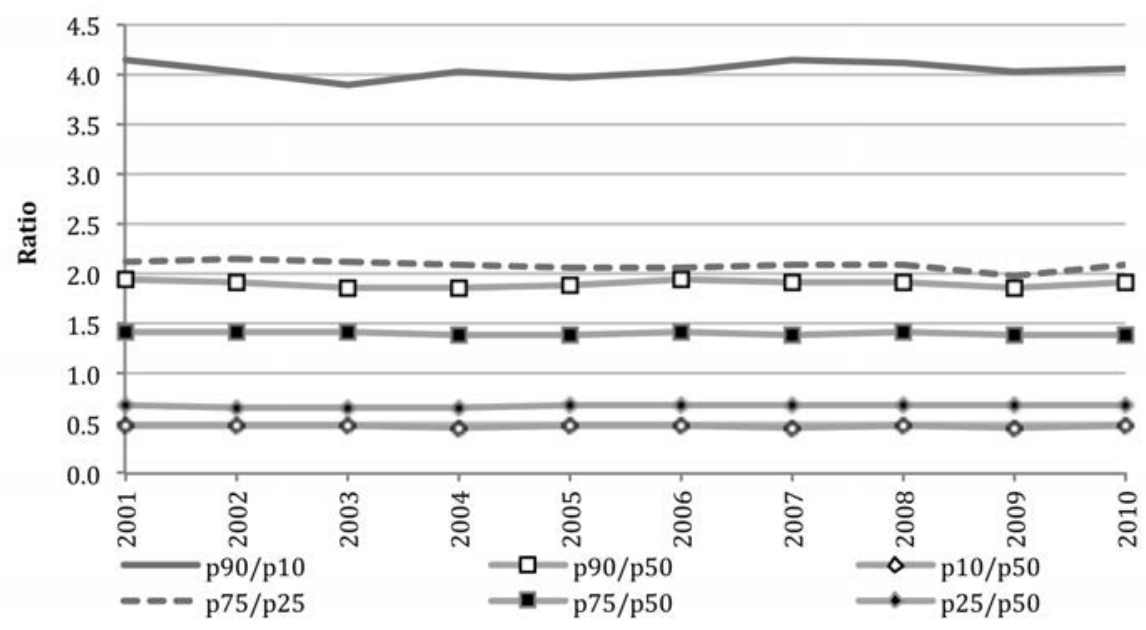

Figure 16 HILDA, Equivalised disposable income, excluding negative and zero observations, selected income ratios, 2001-2010

Note: Excludes records with a negative or zero disposable income.

Source: Derived from HILDA Wave 10.0.

The Atkinson and Generalised Entropy measures shown in Figure 17 differ in one important aspect from the Gini in that they require the user to choose a particular parameter which reflects the specific characteristics of inequality they are particularly interested in.

- In the case of the Atkinson measure the $\varepsilon$ value reflects a level of inequality aversion. A higher $\varepsilon$-typically a value of 2 - makes the measure particularly sensitive to changes in inequality at the bottom of the income distribution.

- The choice of the $\alpha$ parameter in the Generalised Entropy measure plays a similar role with more negative values, making the index more sensitive to income shares between those on lower incomes and more positive values, increasing its sensitivity to differences in income shares amongst those with high incomes.

The data suggests an erratic, but overall downward trend in inequality amongst those on lower incomes, especially up until 2008 (Atkinson $\varepsilon=2$ and Generalised Entropy $\alpha=-1$ ) but less change at other points - although the Generalised Entropy measure with $\alpha=2$ lifts somewhat in the latter part of the period, suggesting that there have been some inequality increasing changes in the income share amongst those with higher incomes. 


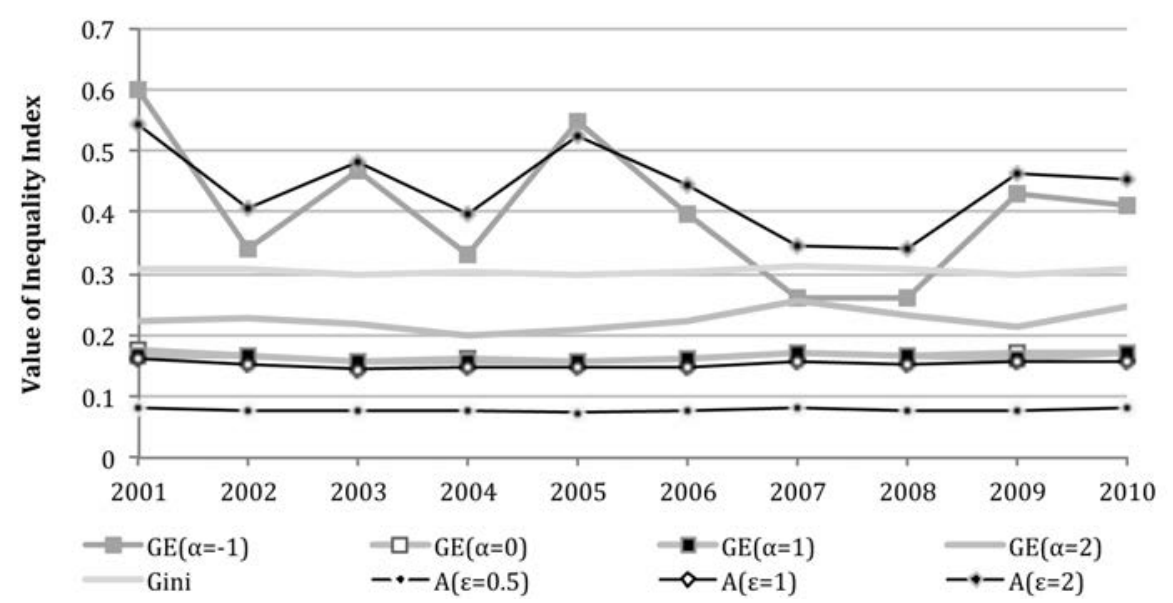

Figure 17 HILDA, Equivalised disposable income, excluding negative and zero observations, selected inequality measures, 2001-2010

Note: Excludes records with a negative or zero disposable income.

Source: Derived from HILDA Wave 10.0.

Figure 18 presents two further assessments of inequality trends from the HILDA survey. For these a balanced panel has been used - that is looking at the experience of those for whom data are available for all waves of the HILDA survey. In this analysis the population has been divided into three cohorts those who were under 25 years in Wave 1, those aged 25-49 years at that time and those aged 50 years and over. This was done as it would be anticipated that these groups may have different experiences over time - the first in terms of leaving parental homes and establishing their own households and participating in the workforce, the third in regard to withdrawal from the work force, with the second representing a group which was likely to have continuously high levels of participation.

Two series are plotted for each of these groups. The first is, for each year, the Gini coefficient for current equivalised disposable income in that year. The second is the Gini coefficient of people's average income over the whole ten-year period..$^{20}$ This latter, for all cohorts, sits well below the annual data. This suggests that income is more evenly distributed when a longer time period is considered, or put another way, that cross-sectional analysis of income distribution picks up some transient elements of income, or errors in the reporting of this. Using the

20 As in all of the analyses involving equivalised measures, the analysis is undertaken on the basis of population weighting, effectively allocating to each person within a household the equivalised income of the household in which they live at that point in time. In this analysis it is the average of these which has been used, even where it involves people who may have lived in a number of different households over the period. 
average of income over the ten-year period produces estimates of the Gini which are 0.050 below the annual figures. For example, over the ten-year period the annual figures for the Gini for the total balanced panel range between 0.301 and 0.327, with an average of 0.311, the Gini for income aggregated over the period is 0.259 . This clearly indicates that income inequality when viewed over a longer time scale is not as severe as shorter term snapshots indicate. ${ }^{21}$

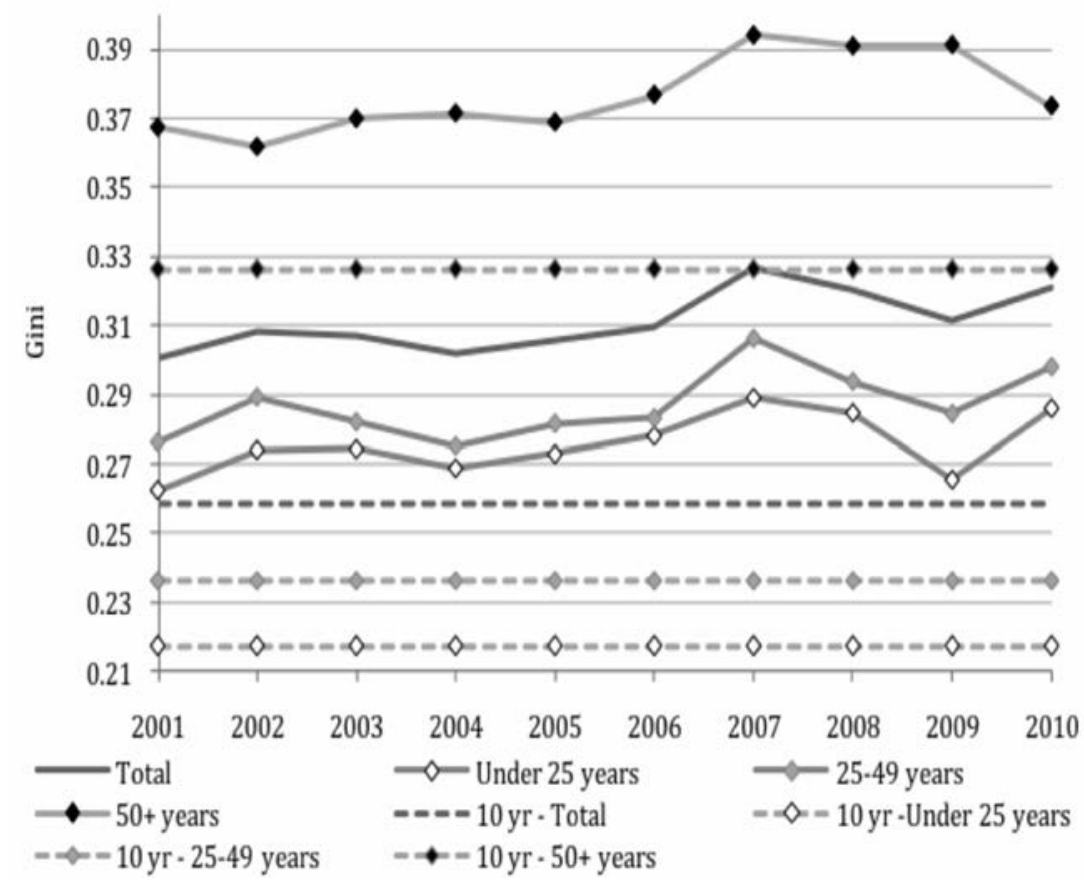

Figure 18 HILDA, Equivalised disposable income, balanced panel, population cohorts based on age in Wave 1, within group Gini, 2001-2010

Source: Derived from HILDA Wave 10.0.

Returning to the annual estimate a second feature of this chart is that, in contrast to the cross-sectionally weighted analysis, there is some suggestion of increasing inequality over the period. This is particularly marked in the 25-49 year-old entry age cohort where the Gini has increased from 0.276 to 0.284. However, for all series, the level of inequality in the second half of the decade is higher than in the first.

21 For this analysis, income in each year has simply been adjusted for changes in the CPI to produce time consistent real values. An alternative approach would be to also include a time discount value to reflect the tendency of individuals to prefer current over future consumption. 


\section{An overall perspective}

Figure 19 plots the Ginis for a selection of the major income series together. Although individual series show considerable volatility and there are periods of marked inconsistency between series, it is not unreasonable to conclude, with the exception of the cross sectional series derived from HILDA, that there has been a general upwards shift in the Gini coefficient, in particular since 1990. The magnitude of this is around 0.025. Recent OECD analysis reports that between 2000 and the late 2000s there were increases in inequality of a similar magnitude in Denmark (0.022), Germany (0.031), Switzerland (0.024) and the US (0.021); conversely there were marked falls in Greece (-0.038), Spain (-0.025), and Great Britain (-0.018) (OECD 2011).

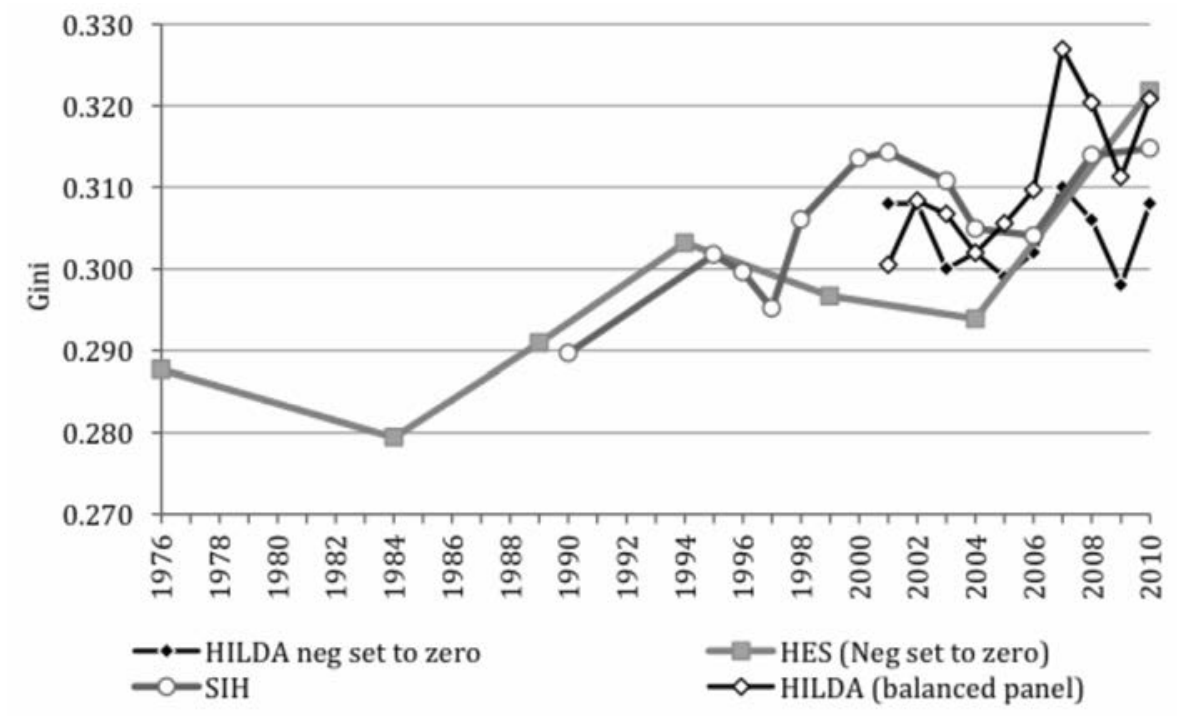

Figure 19 HES, SIH and HILDA, equivalised disposable income, Gini

Notes: HES, series derived from HES CURFs to maximise backwards compatibility, negative household incomes set to zero.SIH: series derived from SIH CURFs, 1990 \& 1994-95 using 1990 basis, 1996-2008 using 1994-95 basis, 2010 using 2005-06 basis. HILDA derived from wave 10.0, a) using cross-sectional weights negative incomes set to zero; b) balanced panel using longitudinal weights.

Source: Derived from HES, SIH and HILDA Wave 10.0.

Perhaps more significant to wellbeing, these shifts in income distribution in Australia, in particular since 2000, have been accompanied by very strong real income growth. This has resulted in households, across the income distribution, having increased resources for consumption and other purposes. 


\section{What impacts on the income distribution?}

This section addresses the question: what are the factors which contribute to the patterns of income distribution seen in the previous section and changes in these over time? In particular it considers the roles of the tax and transfer systems.

The approach used for this is factor decomposition of the Gini coefficient using the 'natural decomposition' approach proposed by Shorrocks (1982). This takes the final distribution of income, typically disposable income, and seeks to identify the relative contributions of each of the components of income to this distribution. In essence it performs this by considering the covariance between the distribution of this particular income component, and the distribution of the population as ranked by the aggregate concept of income.

This however is not the only approach which is available, and a range of different approaches have been developed across the literature. These include:

- Lerman and Yitzhaki (1985) propose the use of a relative marginal effect or elasticity of inequality to a source income - as a focus for decomposing the effect of different sources. This does not consider the decomposition of the existing income components per se but rather considers the impact of a marginal uniform proportional shift in any one source of income on inequality;

- A 'sequential accounting decomposition' of inequality. This involves the derivation of a sequential set of income estimates, adding an additional source each time, then calculating the inequality measure for these and ascribing the change in inequality to the additional source of income. This approach is commonly seen in OECD publications.

- Shapley decomposition (Chantreuil and Trannoy 2013; Shorrocks 2013) this uses a game theory approach repeating games by eliminating components (replaced by the mean or zero) and then uses the average value derived from all possible sequences to estimate the relative contribution.

- Lastly there are a number of regression-based approaches to decomposition as well as various non-parametric approaches.

As hinted at by the existence of this range of methods, even across the most recent literature, there is limited consensus on the most appropriate methodology. This is far from trivial as the results of any decomposition can be very sensitive to the approach given and individual approaches may provide markedly different estimates of the relative contribution of components. In addition there are reasonable grounds for having strong reservations around most of the methods. Some aspects of this are discussed further in Appendix A. 
Although there are arguments for using a number of the approaches, the natural decomposition has been adopted in this paper for a number of reasons. In the first instance, in parts of the analysis up to ten sources of income are considered. The sensitivity of the sequential approach to the order in which components are included makes it poorly suited to this approach. Secondly there is a strong intuitive attraction to the focus in the natural decomposition methodology on the relationship of the income element being considered and the final income distribution, rather than considering distributions of the population which, as in the sequential approach, are re-ranked in each iteration as additional elements are included. In addition the approach provides a direct linkage to the calculations of the marginal effect - with this latter providing a useful tool for the consideration of policy options, rather than just being a descriptive approach.

Finally, in considering this type of decomposition of inequality by source, it needs to be emphasised that only direct effects are being described, and that causation is much more complex. Hence, while these measures, for example, seek to describe the actual quantitative effect of tax paid to the final distribution of income, this is quite a different question to the actual impact of taxation on the distribution of income which includes a diversity of behavioural and other responses (Creedy and Hérault 2012).

\section{Disposable income}

In 2010 the Gini coefficient of equivalised disposable household income, as derived from the HES, was 0.329. This can be decomposed, as shown in Figure 20, into the following contributions: wage and salaries 0.382 , income from a person's own business 0.030, from salary sacrificed amounts of earnings from these two sources 0.017 , investment income 0.046 , superannuation 0.012 , other income 0.002. Offsetting these, income support payments made a negative contribution of -0.041 , family payment -0.012 , and income tax -0.108 . Private transfers made a very small positive contribution of 0.001 . 
18. Changes in Inequality in Australia and the Redistributional Impacts of Taxes and Government Benefits

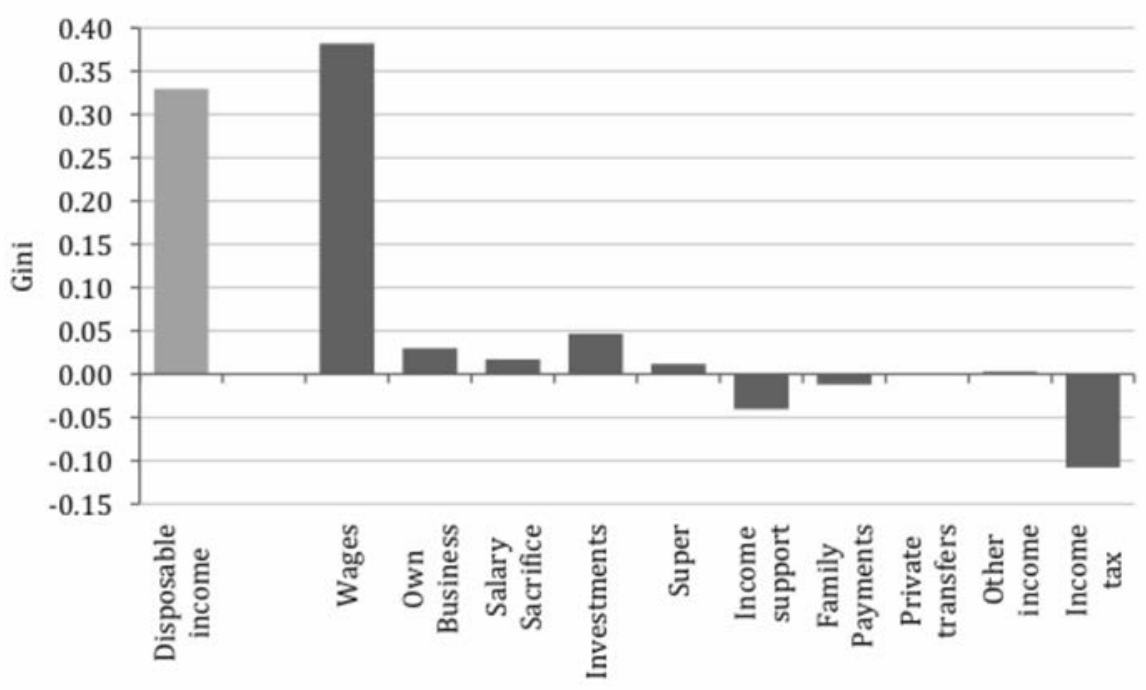

Figure 20 HES, Equivalised disposable income, Gini decomposition by source, 2010

Source: Derived from ABS HES 2009-10 CURF.

That is, the final Gini of 0.329 reflects the impact of the negative -0.161 effect of the tax transfer system on the 0.490 Gini of private income, with the bulk of this effect resulting from the progressive nature of the income tax system.

As discussed in Appendix A, alternative approaches to the decomposition provide different estimates of the relative role of the tax and transfer system in contributing to the lessening of inequality. In particular the sequential accounting approach suggests a stronger role for transfers. In approaching this from a policy perspective there is also merit in considering the Lerman and Yitzhaki relative marginal effect. This is derived directly from the natural decomposition, being the proportional share of the contribution to the inequality of the income source less its share of income. Taking this further transformation, the contribution of income tax of -0.108 represents -32.8 per cent of the overall Gini. Subtracting the income tax share of disposable income (-18.6 per cent) from this, generates an elasticity of -14.2 per cent. The same transformation on the combined effect of transfers is $\mathbf{- 2 8 . 2}$ per cent. This indicates that a uniform proportional change in transfers will have a stronger effect on the distribution of income than a similar change in taxation.

\section{Role of second earners}

This form of decomposition can be undertaken in many different ways to look at the effect of different income sources. Given earlier discussion of the changing 
composition of employment in couple households, Figure 21 splits the effect of earned income (wages and salaries and own business including salary sacrifice) between first and second and other earners (with the first earner being defined as the person in the household with the highest earned income).

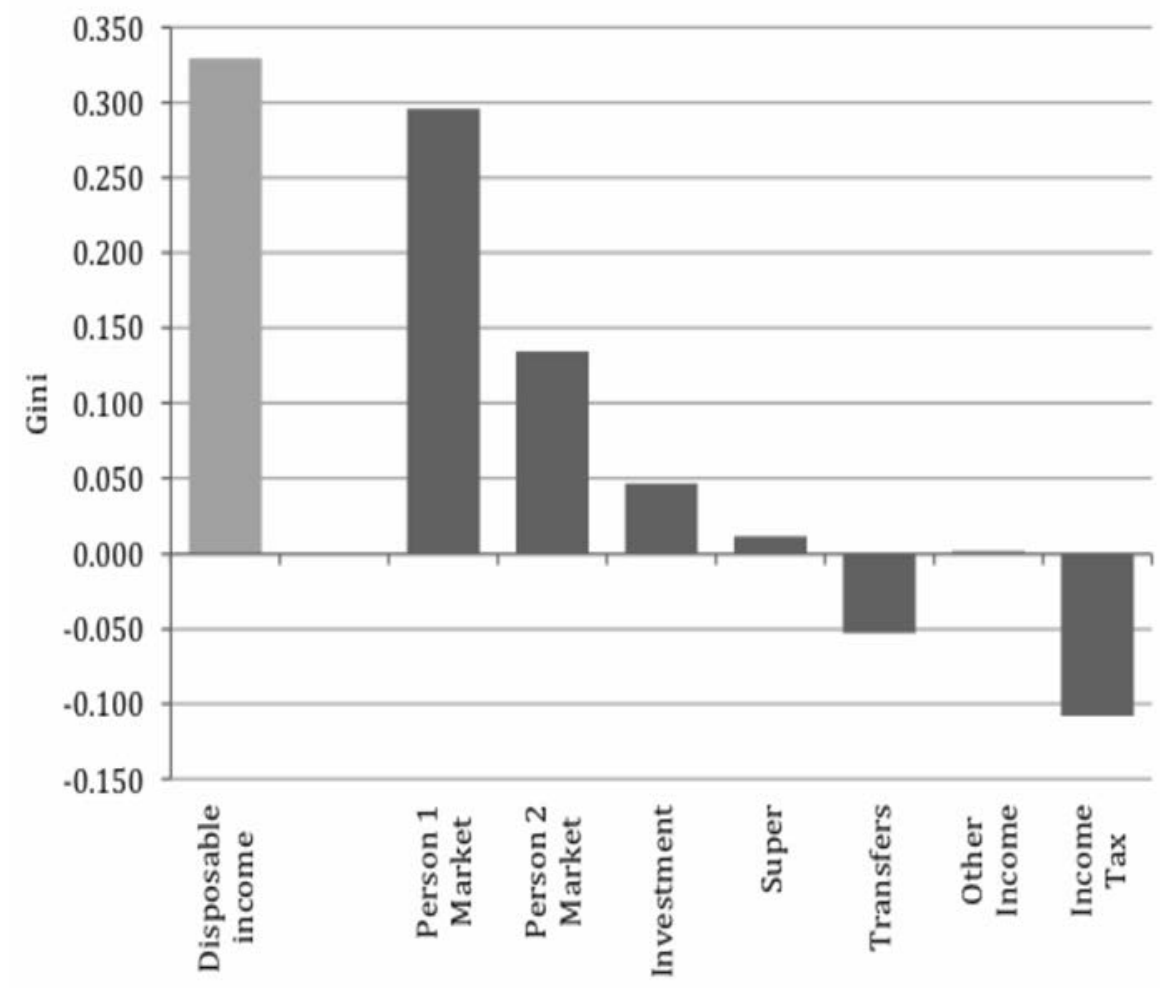

Figure 21 HES, Equivalised disposable income, Gini decomposition by source - impact of first and second earner income, 2010

Source: Derived from ABS HES 2009-10 CURF.

In this case we see that the distribution of income to the first earner contributes 0.296 to the disposable income Gini, while that of the second and other earners adds a further 0.134. Given that first earners contribute on average 2.7 times the income of second and subsequent earners, their relative contribution to the Gini of 2.2 times, suggests that the incomes of second and subsequent earners add disproportionately to inequality across households. ${ }^{22}$

22 The extent of this may be overstated as a consequence of the use of concepts of income and of equivalence scales which do not take account of the costs of employment. That is, under the approach used here it is assumed that two households with the same disposable income and the same household structure are in equivalent situations regardless of whether one or two people (or indeed no person) is in employment. 
The role of second and further income earners in shaping the income distribution is further considered in Figure 22. This plots, for vingtile groups, the value of income derived from the above sources. While employment income for the first person plays a significant role from the fifth vingtile upwards, ${ }^{23}$ second earner income only makes a substantial contribution from the ninth vingtile, where it represents around 23 per cent of the earned income of the household. This proportion then increases to reach 36 per cent of the earned income of households in the sixteenth vingtile before declining to 24 per cent of the earned income of households in the top vingtile. ${ }^{24}$

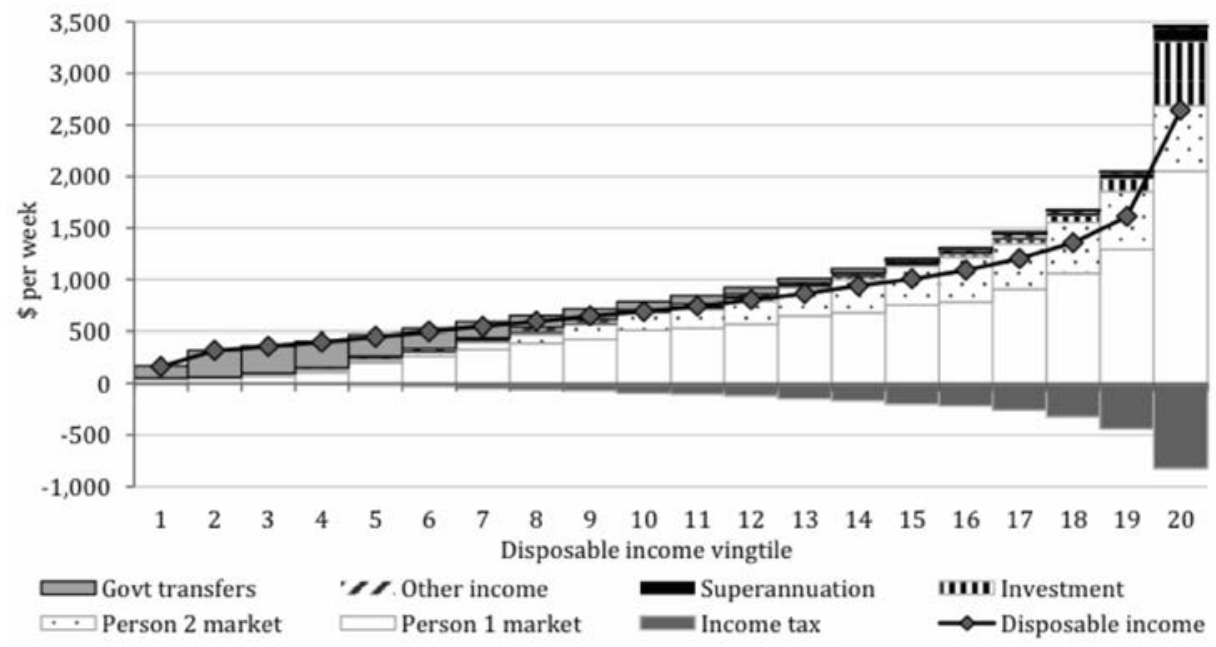

\section{Figure 22 HES, Components of equivalised disposable income, by income vingtile, 2009-10}

Source: Derived from ABS HES 2009-10 CURF.

Also apparent in the chart is the extent to which superannuation and investment income flows to higher income households. Almost 80 per cent of all investment income is received by the 20 per cent of households with the highest disposable incomes, with just over 58 per cent flowing to the five per cent of households that comprise the top vingtile. While the distribution of superannuation is not quite so marked, nevertheless some 44 per cent flows to those in the top 20 per cent of the income distribution, and a quarter to those households in the top five per cent. ${ }^{25}$

23 In technical terms, as the data are population weighted each vingtile represents five per cent of the population living in households with these characteristics. For convenience in discussion this is presented in terms of the vingtiles representing five per cent of the households.

24 While there is some evidence of second earners across all of the vingtiles, the net contribution of these in the lower vingtiles is small. In the first vingtile, because the first and second earner have been defined on the basis of relative earnings, while the average earnings of the first person (as an average across all of the households) is $\$ 40$ per week, this is offset by an average negative income of $-\$ 8$ for second earners.

25 This result is likely to represent the history of superannuation rather than as a prospective finding for the future impact of superannuation. It is probable that this distribution reflects the fact that until the 


\section{Broader concepts of income}

Government intervention in the relative wellbeing of households is not limited to direct cash transfers and income tax. It also includes government benefits in kind - such as health, education and other welfare services, and the impact of indirect taxes including the GST. In addition those households in owner occupied housing gain a flow of services from this. These additional elements generate a broader concept of total income.

The value of these services is estimated by ABS and available in the HES CURF (see ABS 2012). ${ }^{26}$

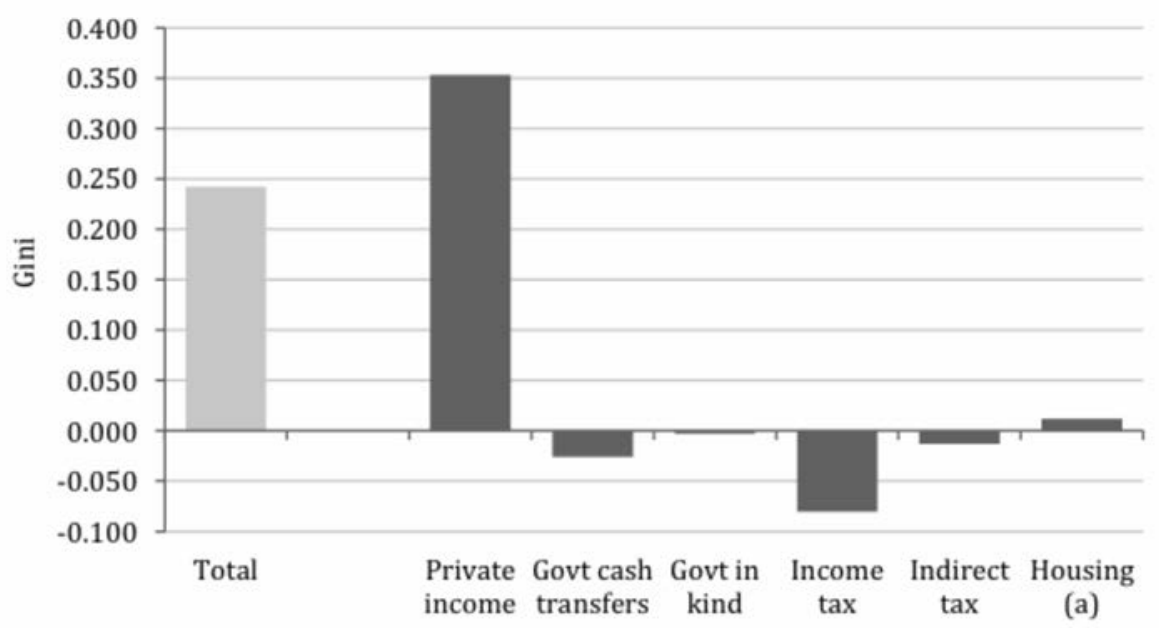

Figure 23 HES, Total income, Gini decomposition, 2009-10

(a) Imputed value of home ownership and private housing subsidies.

Source: Derived from ABS HES 2009-10 CURF.

When this broader notion of income is used, the Gini coefficient falls to 0.242 - substantially below the 0.329 when income is defined in terms of disposable

introduction of the superannuation guarantee, the main groups with superannuation were relatively well-paid employees in the public sector and selected management positions in some areas of the private sector.

26 Full details of the approach used by the ABS are provided in the cited publication. Government assistance in kind, described by ABS as 'social transfers in kind' are defined by the Bureau to 'consist of goods and services provided free or at subsidised prices by the government. In this study, allocation of social transfers in kind was restricted to those arising from the provision of education, health, housing, social security and welfare services, and electricity concessions and rebates'. The methodology for allocating these to households vary - but in large part they are either allocated on an average basis to those who are known to receive services - such as children at school, or allocated on an 'insurance basis' across populations based on known levels of relative use - such as health care which is allocated on the basis of age, gender and state. 
income. ${ }^{27}$ This then can be decomposed into the impact of private income 0.353 , and the value of imputed rent for owner occupied dwellings and privately subsidised rental accommodation 0.012, being offset by government cash transfers -0.026 , government assistance in kind -0.003 , income tax -0.080 and indirect taxes -0.013 .

In considering these results it should be noted that the contribution to the overall Gini of total income from sources such as private income, cash transfers and direct taxation varies from those seen above, with regard to the distribution of disposable income. The key reason for this is that the use of different income measures, as discussed previously, results in a different ranking of households when this is performed using different concepts of income. For example, a household which lives in an owner-occupied house with a number of children attending education may see themselves now ranked in the income distribution above a household with a similar level of income but where the children are not studying and where the household is renting.

\section{Impact of taxes and transfers over time}

As has been seen previously, income taxes and transfers both play a role in countering the degree to which market income is distributed unequally across households. This section is concerned with how this may have changed over time. While having this specific focus, the analysis will also consider other components of income.

\section{HES}

Analysis of the HES data for this purpose has been limited to the period since 1984. The main reason is that the taxation data in the earlier 1976 survey is tax 'as reported' rather than imputed and, on the basis of later surveys and analysis of the apparent changes in the role of income tax, this suggests there is evidence that levels of taxation may be under-reported.

\footnotetext{
27 In this analysis this broader definition of income has again been equivalised by the use of the revised OECD scales. It is less clear, even to the extent these scales may be appropriate for the use of identifying relative needs for disposable income, whether they are entirely appropriate to the use of these broader concepts. For example, given that expenditure on education is allocated to children attending school, the use of a divisor which is more heavily weighted to the number of adults in the household does not seem appropriate. Again there are few simple solutions to this.
} 


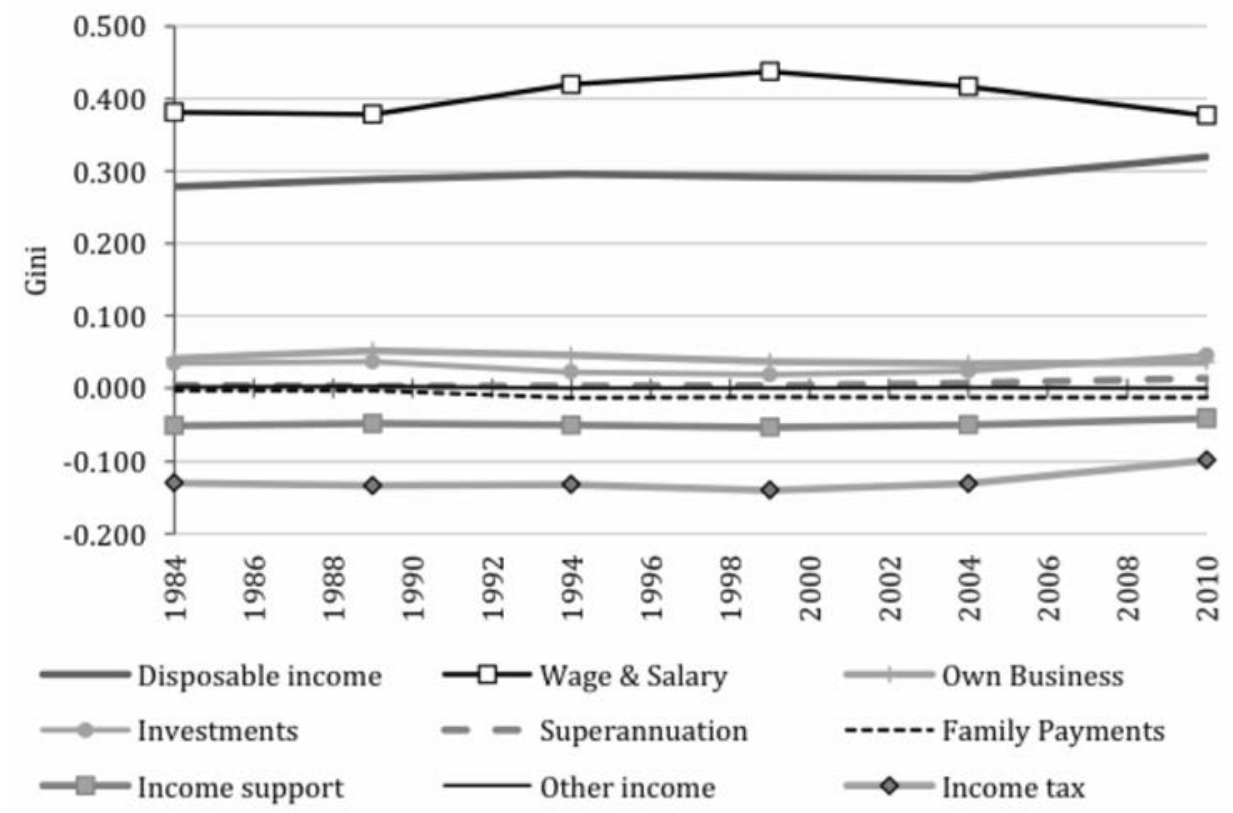

Figure 24 HES, Equivalised disposable income, decomposition of Gini 1984-2010

Source: Derived from ABS HES CURFs 1984 to 2009-10.

Considering in turn the components of income shown in Figure 24 (excepting other income which has only a minor effect on the pattern of income distribution):

- The contribution of wage and salary income to inequality, in addition to being the major contributor, increased from 0.381 in 1984 to a peak of 0.437 in 1999 before declining to 0.377 in 2010, a little below the level it was at the beginning of the period.

- The contribution of own business income to overall inequality was in a range of 0.041 to 0.052 for the first three periods, that is 1984 to 1994 . It then shifted downward to be in the range of 0.034 to 0.037 for the second three periods from 1999 to 2010 .

- Investment income displayed some fluctuation in its contribution to overall inequality over the period making a contribution of 0.034 and 0.037 in 1994 and 1998, before declining to 0.022 in 1994 and 0.018 in 1999, before rising to 0.024 in 2004 and 0.046 in 2010 .

- Superannuation made a slight positive contribution to the overall pattern of inequality of 0.003 to 0.004 up to 1999 before increasing to 0.007 in 2004 and 0.014 in 2010. 
- The impact of family payments was small in 1984 and 1988 at -0.003 in each period, before increasing substantially to -0.013 in 1994 and remaining at or very close to that level over the rest of the period.

- Income support made a relatively consistent offsetting contribution to inequality of around -0.048 to -0.053 over the whole period, except for 2010 where it dropped to -0.041

- Income tax also had a negative impact on the level of inequality over the period. This was in the range of -0.130 to -0.134 for the first three periods, rising to -0.140 in 1999 before declining back to its earlier levels in 2004, before falling very sharply to -0.098 in 2010.

The summary impact of these changes is illustrated in Figure 25. The chart shows, for the period between 1984 and 1999, and then between 1999 and 2010, the change in contribution of each of the components to the Gini coefficient of the distribution of disposable income.

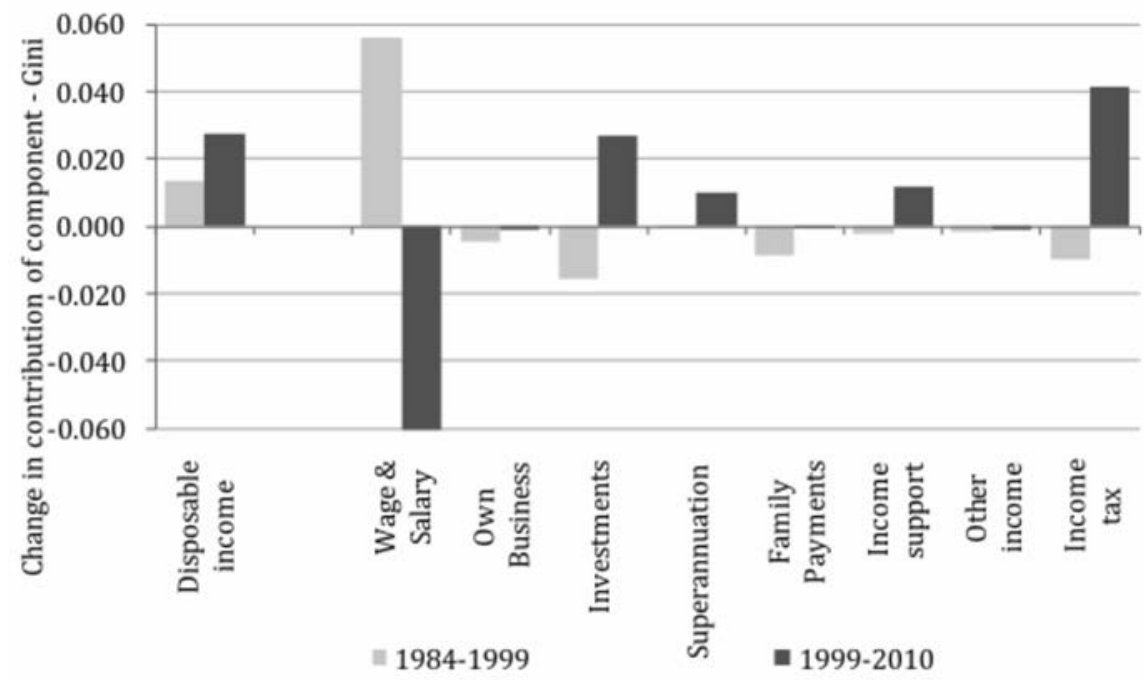

Figure 25 HES, Change in contribution of components of income to overall inequality 1984 to 1999 and $1999-2010$

Source: Derived from ABS HES CURFs 1984-2009-10.

Over the first period the main effect was an increasing contribution towards inequality from wage and salary income offset by declines in the contribution of most other elements. Over the past decade the situation has been quite different: the role of wage and salary income as a contributor to inequality has declined while that of capital income from investments and superannuation has increased, and the offsetting role of income support has fallen. Most marked however has 
been the very large decrease in the offsetting role of taxation (resulting in a positive contribution to the change in inequality). A similar but lesser change is seen in the role of income support payments.

\section{HILDA}

Although HILDA showed a very slight decline in inequality over the past decade - a contrast with the results from the HES and SIH, as shown in Figure 26 the pattern of change in the relative contributions of the components is very similar to that identified in the HES. The contribution to inequality of earned income (from wages, salaries and own business) fell strongly over the period, income from capital (investments and superannuation) increased its impact on income inequality, while income support payments played a less marked role in offsetting inequality. While the decline in the role of income tax in offsetting inequality was not quite as marked as seen in the HES, it remains very strong.

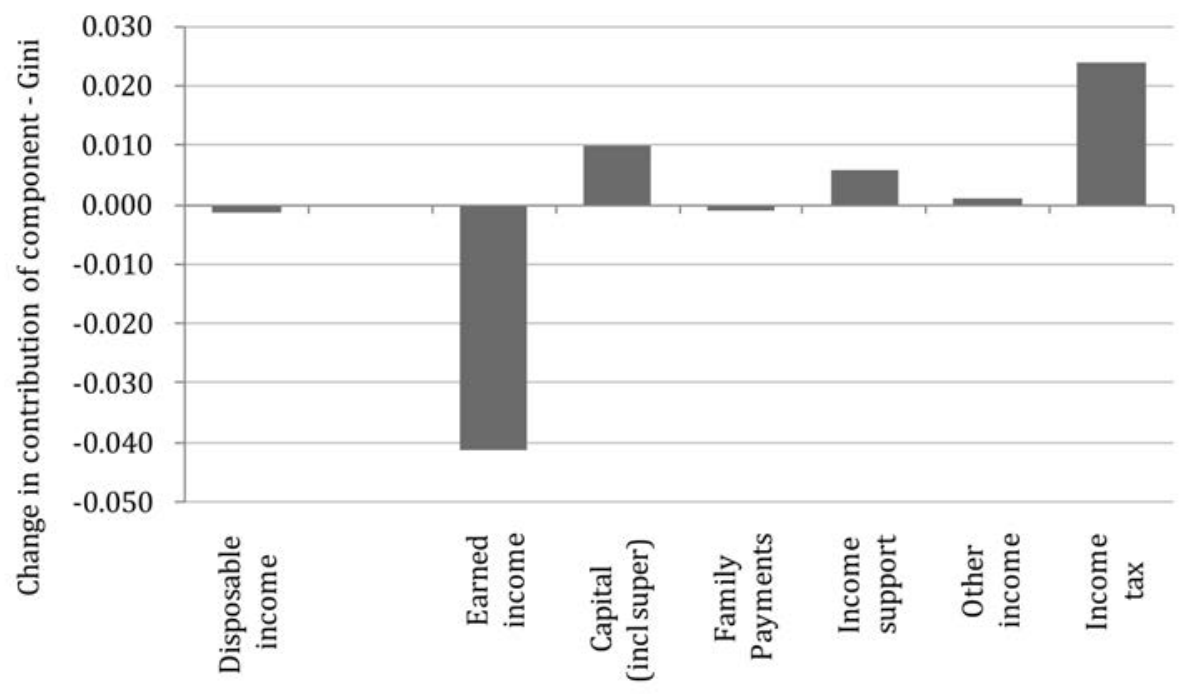

Figure 26 HILDA, Change in contribution of components of income to overall inequality 2001-2010

Source: Derived from HILDA Wave 10.0.

A more detailed analysis of the contributions of these components to inequality over the period is shown in Figure 27. As with the HES data this suggests that most of the decline in the offsetting role of income tax is in the post-2006 period. Although peaking at -0.142 in 2002, the impact of taxation in 2006 remained strong at -0.137 in 2006 before declining to -0.116 in 2010. 
The role of income support varied a little more over the period, although again showing a reduction in its offsetting role. In the early 2000s it was around or above -0.04 before falling to a low of -0.028 in 2009, and rising to -0.034 in 2010 .

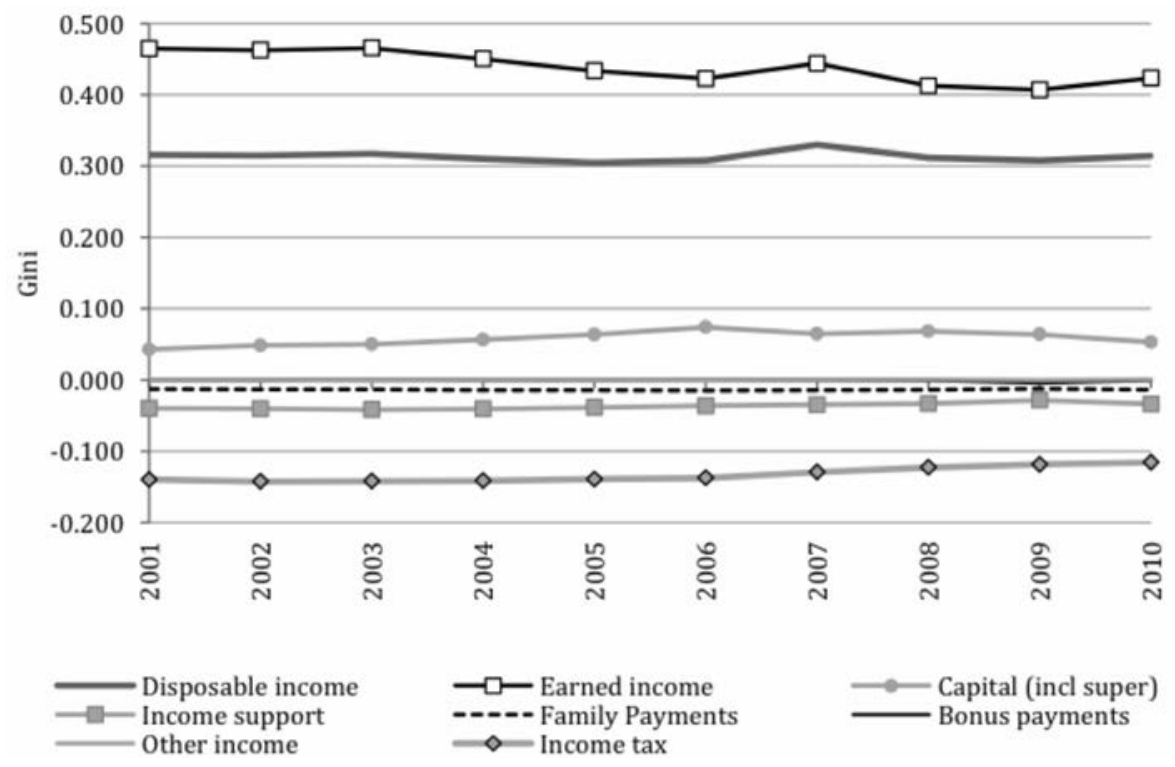

Figure 27 HILDA, Equivalised disposable income, decomposition of Gini 2000-2010

Source: Derived from HILDA Wave 10.0.

\section{$\mathrm{SIH}$}

Figure 28 and Figure 29 show the contribution of income tax to overall inequality as recorded in the SIH, firstly with regard to current income and secondly with regard to annual income. While there are some differences in the period up to 1995, since then both series suggest that there was an increase in the offsetting role income tax played up until around 2000, after which this role diminished. While the two series do not wholly coincide on timing, certainly the pick up was more marked in the latter half of the decade. 


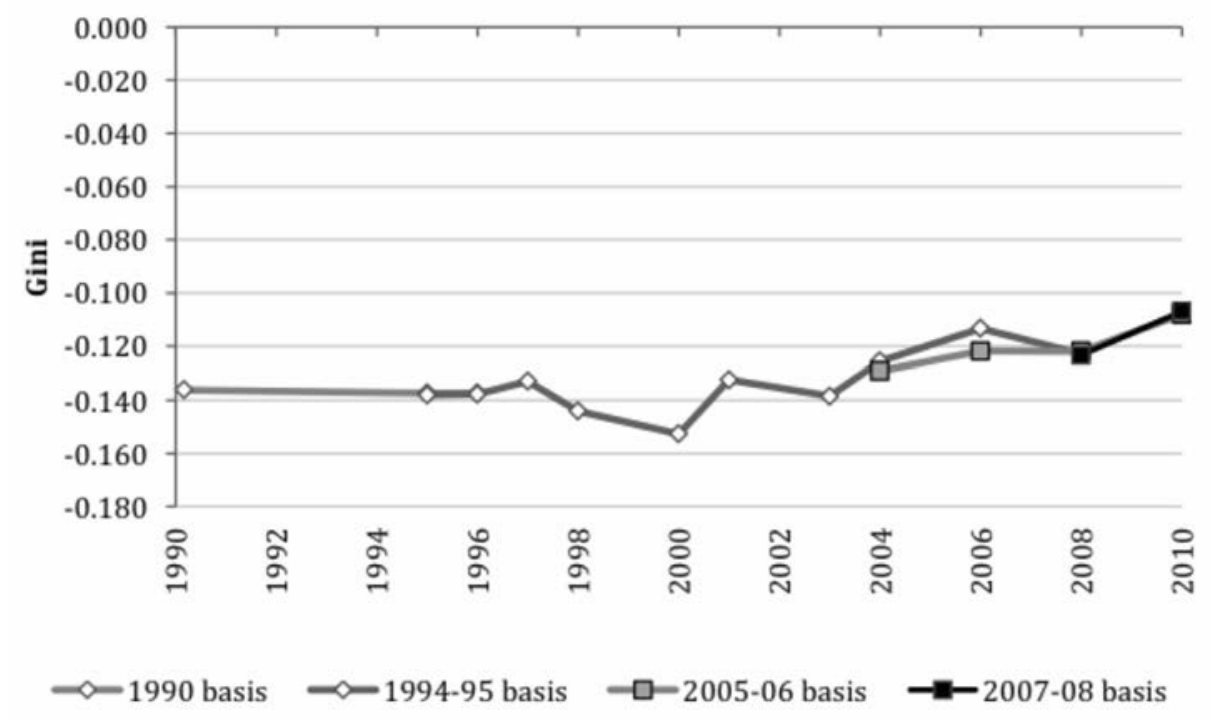

Figure $28 \mathrm{SIH}$, Current equivalised disposable income, contribution of income tax to Gini, using different income definitions, 1990-2010

Source: Derived from ABS SIH CURFs 1990-2010.

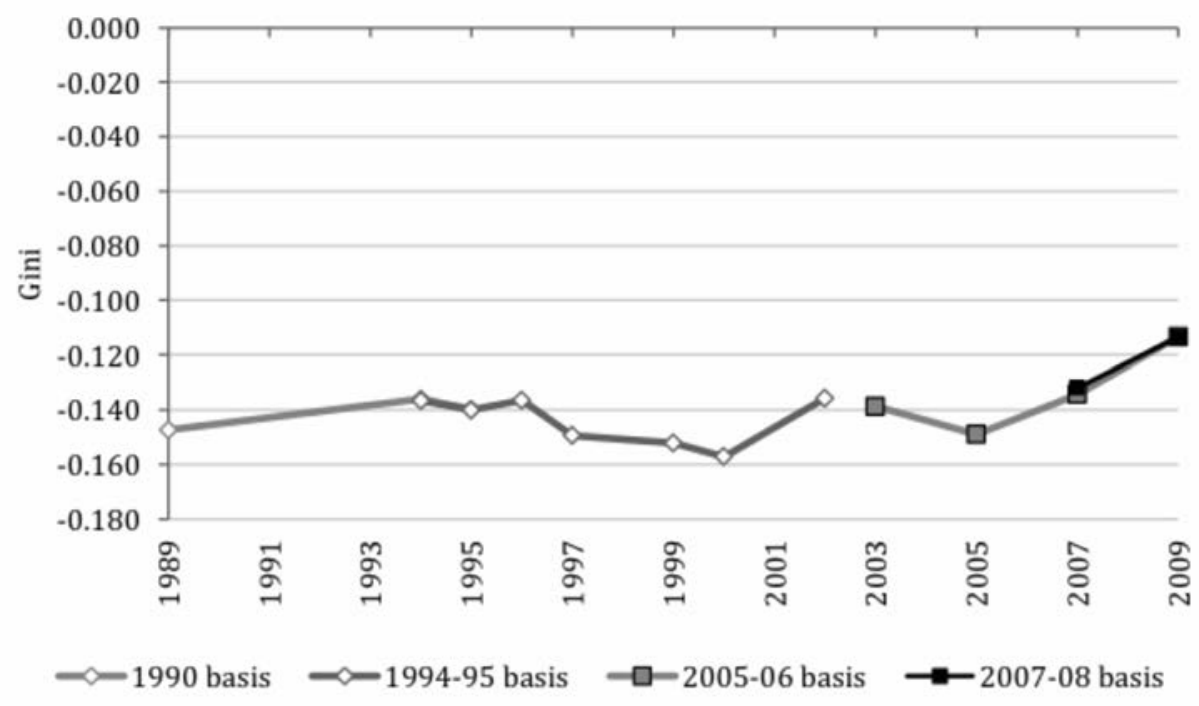

Figure $29 \mathrm{SIH}$, Annual equivalised disposable income, contribution of income tax to Gini, using different income definitions, 1990-2010

Source: Derived from ABS SIH CURFs 1990-2010.

The annual data suggests that the decline from 2000 has been around 0.044 with most of this (-0.036) occurring between $2005(-0.149)$ and $2009(-0.114)$. 
The current data series suggests a decline of 0.025 to 0.045 to the 2010 level of -0.107 , depending upon whether $2001(-0.153)$ or $2000(-0.132)$ is used as the base year.

These estimates compare with 0.042 from the HES for the period between 1999 and 2010, and 0.024 from HILDA between 2001 and 2010. In looking at the pattern of the data, and in particular the movement in 2000, one issue which needs to be considered in explaining these trends is the impact of the changes in direct taxation associated with the introduction of the GST, as well as the ongoing changes to the taxation system that have been documented earlier.

\section{Conclusions and reflections}

Analysis of the distribution of income in Australia suggests that over recent years there has been an increase in income inequality and that the traditional tools of income distribution, progressive income tax and transfer payments have been playing a lesser role in counterbalancing the impact of the distribution of other sources of income. Indeed the decomposition of the sources of inequality would suggest that the decline in the function played by these has been the main factor contributing to the increase in inequality.

Specifically, while the results vary from source to source and the methodology used, the analysis indicates:

- Income inequality in Australia, as measured by the Gini, has risen by some 0.02 to 0.03 since the mid 1990s with much of this increase occurring since the mid 2000s. In the case of the SIH, using current data, this is an increase from 0.295 to 0.314 .

- In the past decade the extent to which income tax reduces inequality has fallen. The change identified represents a decrease in its offsetting impact on the Gini of some 0.02 to 0.04

- A similar reduced impact is seen in the role of transfer payments. In this case the reduction in the offset to the Gini is around 0.005 to 0.01 .

- Taken together these factors would appear to be responsible for the overall decline, although it is noted that many other components have moved in different directions at the same time. However all three surveys considered in the analysis indicate that changes in the distribution of wage and salary income over the past decade has been towards equalising the income distribution.

This finding though needs to be taken with some caution. 
- On technical grounds the measurement of income is fraught with both practical and conceptual limitations, and while income may be better measured in many household surveys than it has in the past, this has brought with it problems in building consistent datasets to allow for the analysis of income over time. In addition as a measure of household resources, current income measures do not account well for some dimensions such as capital gains, and few surveys identify well the range of non-cash benefits which play an important role in wellbeing. It is also well established that for many households income does not reflect either their level of consumption, or of wellbeing. An additional set of technical problems arises in measuring income inequality. In particular the use of single value measures of inequality does not capture the different ways in which inequality can occur. These technical problems of inequality measurement are even more complex when attempting to identify the contribution of different income components to final income inequality.

- While inequality would appear to have increased more strongly since the early to mid 2000s, this has also been accompanied by a strong increase in household incomes which, while favouring higher income households, has been well distributed across the income distribution including those households with the lowest incomes.

- It is difficult, in the context of income inequality, to make normative judgements about some of the factors which may have contributed to this. For example the increasing proportion of dual income households is likely to have increased the level of inequality relative to those with one income. Similarly population ageing had resulted in an increase in the number of retired incomes, many of which are drawing upon superannuation and other savings, as well as potentially facing lower income needs.

- More specifically the lesser role of the government transfers in redressing income inequality needs to be seen in the light of a decline in the proportion of the population which is in receipt of these payments and the lesser reliance by households on these payments as their major source of income. In the case of the role of taxation, again the lesser role of income tax in income distribution must be considered in the context of changes to taxation policy which have seen an overall reduction in the average tax rate from 23.1 per cent to 21.0 per cent with particularly strong reductions in the average rate of tax paid by those in the lower half of the distribution of taxpayers.

These cautions do not however mean that the question of income distribution should simply be ignored, but rather argues a need for us to improve our techniques and data, and not treat any results in isolation from a wide range of other economic and social objectives and priorities. 
Further, in forming any judgements about income inequality and its trends, the question must be asked as to why one is concerned? It can be suggested that in itself income inequality, within certain bounds, is of relatively little import, but rather its study serves more as a guide to two other questions. The first is whether it is a symptom of some more fundamental problem within society; the second is whether it brings with it consequences which may be adverse to society.

Related to this is a final question: even if trends in income distribution provide a means for exploring these questions, is its use as an indirect approach appropriate, or should attention be given more directly to other forms of inequality? These might include opportunities for education, access to health care, ability to engage in leisure and other activities which a person may value, freedom from discrimination or ability to exert power. While it can be argued that income plays an important role in achieving some of these opportunities, for others this may not necessarily be the case.

\section{References}

Araar A (2006). On the decomposition of the Gini Coefficient: an Exact Approach, with an illustration using Cameroonian data, Centre interuniversitaire sur le risque, les politiques économiques et l'emploi, Working Paper 06-02.

Araar A and Duclos J-Y (2013). User Manual DASP version 2.3, DASP: Distributive Analysis Stata Package, Université Laval, PEP, CIRPÉE and World Bank .

Australian Bureau of Statistics (1986). 1984 Household Expenditure Survey, Australia, Summary of Results, Cat No 6530.0, ABS, Canberra.

Australian Bureau of Statistics (1987). 1984 Household Expenditure Survey, Australia, Effects of Government Benefits and Taxes on Household Income, Cat No 6537.0, ABS, Canberra.

Australian Bureau of Statistics (2010). Standards for Income Variables, 2010, Cat No 1287.0, ABS Canberra http://www.abs.gov.au/AUSSTATS/abs@.nsf/ Lookup/00AD7C0C516A9508CA2576E400144852?opendocument, ABS, Canberra.

Australian Bureau of Statistics (2011). Education and Work Australia, May 2011, Cat No 62270DO001_201105, ABS, Canberra.

Australian Bureau of Statistics (2011). Household Income and Income Distribution, Australia, 2009-10, SIH 2009-10 Detailed Tables Cat No 65230DO001, Table 3, ABS, Canberra. 
Australian Bureau of Statistics (2012). Household Expenditure Survey and Survey of Income and Housing, User Guide, Australia, 2009-10, Cat No 6503.0, ABS, Canberra.

Australian Bureau of Statistics (2012). Employee Earnings, Benefits and Trade Union Membership, Cat No 6310.0, ABS, Canberra.

Australian Bureau of Statistics (2012). Labour Force, Australia, Detailed Electronic Delivery, Oct 2012, Cat No 6291.0.55.001, ABS, Canberra.

Australian Bureau of Statistics (2012). Government Benefits, Taxes and Household Income, Australia, 2009-10, Cat No 6537.0, ABS, Canberra.

Australian Bureau of Statistics (Various years). Employee Earnings and Hours, Australia, Cat No 6306.0, ABS, Canberra.

Australian Taxation Office (2003). Taxation Statistics 2000-2001, Australian Taxation Office, Canberra.

Australian Taxation Office (2012a). Individual income tax rates for prior years, http://www.ato.gov.au/content/73969.htm last accessed 10 November 2012.

Australian Taxation Office (2012b). Individual income tax rates http://www.ato. gov.au/individuals/content.aspx $\mathrm{doc}=/$ content/12333.htm last accessed 10 November 2012.

Australian Taxation Office (2012c). Taxation statistics 2009-10, Australian Taxation Office, Canberra.

Brewer M and Wren-Lewis L (2011). Why did Britain's households get richer? Decomposing UK household income growth between 1968 and 2008-09, IFS Briefing Note 125, Institute of Fiscal Studies.

Chantreuil F and Trannoy A (2013). "Inequality decomposition values: the tradeoff between marginality and efficiency", Journal of Economic Inequality, 11: 83-98.

Commonwealth Department of Housing, Community Services and Indigenous Affairs (FaHCSIA) (2012). Guide to Social Security Law Version 1.191, http:// guidesacts.fahcsia.gov.au/guides_acts/ssg/ssg-rn.html

Cowell FA and Fiori CV (2010). Inequality Decompositions, Amsterdam, AIAS, GINI Discussion Paper 4.

Creedy J and Hérault N (2012). Decomposing Inequality and Social Welfare Changes: The Use of Alternative Welfare Metrics, Working Papers in Public Finance 06/2012 Victoria University of Wellington. 
Fuest C., Niehues J., Peichl A. (2010). “The Redistributive Effects of Tax Benefit Systems in the Enlarged EU", Public Finance Review, 38 (4): 473-500.

Garcia-Peñalosa C and Orgiazzi E (2013). Factor Components of Inequality: A Cross-Country Study, Aix Marseille School of Economics Working Paper 2013 -Number 18.

Heshmati A (2004). A Review of Decomposition of Income Inequality, Discussion Paper No 1221, IZA, Bonn.

Immervoll $\mathrm{H}$ and Richardson L (2011). Redistribution Policy and Inequality Reduction in OECD Countries: What Has Changed in Two Decades? Discussion Paper No. 6030, IZA Bonn.

Immervoll H, Levy H, Lietz C, Mantovani D, O'Donoghue C, and Sutherland $\mathrm{H}$ (2005). Household Incomes and Redistribution in the European Union: Quantifying the Equalising Properties of Taxes and Benefits, EUROMOD Working Paper No. EM9/05.

Je्drzejczak A (2008). "Decomposition of the Gini Index by Sources of Income", International Advances in Economic Research, 14:441-447.

Jenkins SP and Van Kerm P (2009). "The Measurement of Economic Inequality," in The Oxford Handbook of Economic Inequality Salverda W, Nolan B and Smeeding TM (eds), Oxford University Press.

Kimhi A (2009). On the Interpretation (and Misinterpretation) of Inequality Decompositions by Income Source, Discussion Paper No 9.09, The Center for Agricultural Economic Research, The Hebrew University of Jerusalem.

Lambert PJ (2013). “Mini-symposium on the Shapley value: The 1997 paper by Frédéric Chantreuil and Alain Trannoy, and the 1999 paper by Anthony F. Shorrocks", Journal of Economic Inequality, 11: 79-82.

Lerman RI and Yitzhaki S (1985). "Income Inequality Effects by Income Source: A New Approach and Applications to the United States", The Review of Economics and Statistics, Vol 67 No 1: 151-156.

OECD (2011). Divided we stand, Why inequality keeps rising, OECD, Paris.

OECD (2011). Factbook 2011: Economic, Environmental and Social Statistics, OECD, Paris.

Okamoto M (2011). "Source decomposition of changes in income inequality: the integral-based approach and its approximation by the chained Shapleyvalue approach", Journal of Economic Inequality, 9: 145-181. 
Sastre M and Trannoy A 2002). "Shapley Inequality Decomposition by Factor Components: Some Methodological Issues", Journal of Economics, Supplement 9: 51-89.

Sen, AK (1995). Inequality Reexamined, Harvard University Press.

Shorrocks AF (2013). "Decomposition procedures for distributional analysis: a unified framework based on the Shapley value", Journal of Economic Inequality, 11: 99-126.

Suoniemi I (2000). Decomposing the Gini and the variation coefficients by income sources and income recipients, Labour Institute for Economic Research, Helsinki.

Treasury (2010). Intergenerational Report 2010 Australia to 2050: future challenges, Treasury, Canberra.

U.S. Census Bureau (2012). Median weekly earnings of part-time wage and salary workers by selected characteristics Table P-38, Current Population Survey, Annual Social and Economic Supplements. http://www.bls.gov/cps/ cpsaat38.pdf

Wang C and Caminada K (2011). Disentangling income inequality and the redistributive effect of social transfers and taxes in 36 LIS countries, Munich Personal RePec Archive Paper no 32861.

Wilkins, R, Warren, D and Hahn, M (2009). Families, Incomes and Jobs, Volume 4: A Statistical Report on Waves 1 to 6 of the Household, Income and Labour Dynamics in Australia Survey, Melbourne Institute of Applied Economic and Social Research, The University of Melbourne.

Wilkins, R, Warren, D, Hahn, M and Houng, B (2010). Families, Incomes and Jobs, Volume 5: A Statistical Report on Waves 1 to 7 of the Household, Income and Labour Dynamics in Australia Survey, Melbourne Institute of Applied Economic and Social Research, The University of Melbourne.

Wilkins, R, Warren, D, Hahn, M and Houng, B (2011). Families, Incomes and Jobs, Volume 6: A Statistical Report on Waves 1 to 8 of the Household, Income and Labour Dynamics in Australia Survey, Melbourne Institute of Applied Economic and Social Research, The University of Melbourne. 


\section{Appendix A: Alternative approaches to decomposition of inequality by source}

This paper has primarily used the Shorrocks approach to the decomposition of income inequality by source. As has been discussed, this is not the only approach. This attachment compares the results of this methodology with others which have been used in contemporary analysis.

This comparison is illustrated in Table 5. The analysis has been undertaken on current income in the 2009-10 HES survey, and for the purposes of analysis a three-source model has been adopted. This breaks income into private income, government transfers and income tax. In all cases the inequality measure which is being decomposed is the Gini coefficient. The methodologies shown are:

- Shorrocks' factor decomposition as used in the text;

- Lerman and Yitzhaki's (1985) extension of this to identify the relative marginal effect of each of the components. As indicated in the paper, this is not strictly decomposition of the existing income components but rather informs on the potential relative impact of changes in any one of these income sources on the Gini. (As an elasticity it implies, using the value of -0.282 the marginal effect of transfers as shown in the table, that a uniform 10 per cent increase in transfers will result in a 0.009 - or 2.8 per cent reduction in the Gini.);

- Two Shapley decompositions, as this method requires the elimination of particular components of income in its derivation it is necessary to replace the component with a constant. Two methods are usually proposed, the first is the simple elimination of the component - that is setting it to zero, the second is setting it to its mean value;

- Three examples of the sequential accounting approach to decomposition. As noted this commences with one element of income, estimates the Gini for this, and then adds other elements of income, and recalculates the Gini for these components together. It then identifies the differences between these two Ginis as the contribution made by the additional income component. This sequence is then repeated for additional elements of income. The three models shown use a difference sequencing of private income (P), income $\operatorname{tax}(\mathrm{I})$ and transfers (T). The three sequences shown are Private/Transfers/ Income tax; Private/Income Tax/Transfers; and Transfers/Private/Income tax.

The natural decomposition and marginal effect have been calculated using a user-written Stata routine, the Shapley decomposition has been undertaken using the dsginis command which is part of the DASP add-on package to Stata and the sequential accounting approach has used the Stata ineqdec0 command written by Stephen Jenkins. In all cases data has been equivalised using the 
modified OECD equivalence scale as discussed previously. The first panel of the table shows the decomposition of the Gini (or in the case of the marginal effect the elasticity) and the second, the relative contribution each source of income makes to the income distribution.

Table 5 HES 2009-10, Alternative approaches to decomposing factor components of inequality

\begin{tabular}{|c|c|c|c|c|c|c|c|}
\hline & \multicolumn{2}{|l|}{ Natural } & \multicolumn{2}{|l|}{ Shapley } & \multicolumn{3}{|c|}{ Sequential accounting } \\
\hline & Decomposition & $\begin{array}{l}\text { Marginal } \\
\text { effect }\end{array}$ & Zero & Mean & PTI & PIT & TPI \\
\hline \multicolumn{8}{|c|}{ Gini } \\
\hline Private & 0.490 & 0.424 & 1.400 & 0.318 & 0.471 & 0.471 & -0.297 \\
\hline Transfers & -0.053 & -0.282 & -0.229 & 0.009 & -0.101 & -0.116 & 0.667 \\
\hline \multirow[t]{2}{*}{ Income Tax } & -0.108 & -0.142 & -0.842 & 0.002 & -0.041 & -0.026 & -0.041 \\
\hline & 0.329 & & 0.329 & 0.329 & 0.329 & 0.329 & 0.329 \\
\hline \multicolumn{8}{|c|}{ Relative contribution } \\
\hline Private & 1.487 & & 4.252 & 0.966 & 1.431 & 1.431 & -0.900 \\
\hline Transfers & -0.160 & & -0.695 & 0.026 & -0.306 & -0.351 & 2.026 \\
\hline Income Tax & -0.328 & & -2.557 & 0.007 & -0.125 & -0.080 & -0.125 \\
\hline
\end{tabular}

Source: Derived from ABS HES CURF 2009-10.

As shown there is little consistency in the estimates of the relative contribution to inequality across the methodologies.

In the first instance two of the approaches - the Shapley with mean replacement and the sequential accounting approach which commences with transfer payments - generate results which appear implausible. When eliminated elements of personal income are replaced by the mean value, all components of income are identified as increasing inequality using the Shapley approach. This result has been previously identified by Araar (2006), who notes that the mean replacement approach is most appropriate where the interaction effect between the components is null. This is clearly not the case where income tax is dependent upon the level of private income, and where income support flows primarily to households with inadequate levels of income to support themselves. It is also discussed in Shorrocks (2013: 118), who notes that this zero replacement approach provides a more intuitive analysis of the impact of a uniform poll tax or subsidy. ${ }^{28}$ In the case of the sequential accounting approach the result highlights the sensitivity of this method to the sequence in which income elements are considered.

28 Interestingly the behaviour of the natural decomposition approach to this very impact is the major criticism of the natural decomposition approach in Feust, Niehues and Peichl (2010). 
The second aspect of these approaches is the relative roles of the tax and transfer systems. Whereas the natural decomposition and the Shapley with a zero replacement suggest that the impact of the income tax system on reducing income inequality is double to almost four times that of the transfer system, the sequential accounting approaches suggest the inverse. Depending upon the order in which the decomposition is undertaken, it estimates the role of the tax system to be only 40 per cent to a little over 20 per cent as great as the transfer system. This difference also highlights the sensitivity of the sequential approach to ordering. While it might be possible to argue plausible sequencing to some elements, these often simply represent established accounting identities rather than logical sequences. Further the issues become much more difficult to resolve when multiple sources of income are considered.

While the estimated marginal effect of the transfer system is estimated to be about double that of the income tax system, it is to be recalled that this is an elasticity to a change in the component, and that the actual magnitude of a proportional change in the taxation system is larger than that of a similar change in the transfer system.

The discrepancy between the natural decomposition and sequential approach to decomposition in regard to the role of taxes and transfers is not unique to the Australian income distribution but is rather more deeply embedded in the methodology. Wang and Caminada (2011), in a study of 36 countries included in the Luxembourg Income Study, report that across all of these countries on average transfers account for 85 per cent of the overall redistribution and taxes just 15 per cent - with the only exception being Guatemala (ibid: 14). Fuest, Niehues and Peichl (2010) consider the two methods in a study of redistribution in the EU and in discussion suggest that the difference between the approaches is a function of the normative foundations and that both approaches should be considered.

Finally, as has been suggested previously, caution needs to be taken in the interpretation of these source decompositions as being causal elements. This further step requires much more than a decomposition, including taking into account the behavioural responses of people to the particular components and the effect this may on both the component itself, and on other possible sources of income. 


\section{Appendix B: Notes on data sources}

\section{HES}

The Household Expenditure Survey is the longest standing household survey conducted by the ABS for which regular Confidentialised Unit Record Files are available. The survey was initially developed with the purpose of weighting the Consumer Price Index, although it has increasingly been used for more diverse purposes with latter iterations containing data on wealth and financial hardship. In addition, since 1984 the ABS has also generated estimates of the impact of non-cash government benefits and indirect taxes. The HES was conducted in 1974-75, 1975-76, 1984, 1988-89, 1993-94, 1998-99 2003-04 and 2009-10, and data from all but the first of these have been used in this analysis. ${ }^{29}$

A number of these characteristics make the HES, while smaller in sample size than some other household surveys, an attractive basis for income distribution analysis.

The files have been subject to some editing to attempt to build a more consistent time series.

Over time there have been many changes to the concept of income used in the surveys. Central to these is the inclusion in most recent data of income from overtime and bonuses, better recording of amounts salary sacrificed and the use of current estimates of income from investments and own business, rather than basing these on data from the previous financial year.

In all surveys used in this analysis, other than the 1975-76 survey, income tax data has been imputed. In 1984 while ABS published aggregate data (ABS Cat No 6537.0 1987) showing the imputed values, these have not been included on the CURF. As the difference between the reported average level of tax of $\$ 80.07$ (ABS Cat No 6530.0 1986) and the imputed tax $\$ 91.60$ is quite substantial, an imputation exercise has been undertaken with this being benchmarked to the ABS published series. It is not possible to undertake such an accurate imputation on the earlier file.

While the 2003-04 and 2009-10 data files contain some information on income components in a form which maintains some backward compatibility, data on the imputed value of income tax on these is not provided (or in the case of

29 The 1974-75 HES has been excluded from analysis as it was restricted to state capital cities and Canberra, and ABS has not released a CURF. 
2009-10 is the same as for the current definition); adjustments have been made for this. Other processing has been undertaken to obtain estimates of full-time employment amongst the self-employed in the first two surveys.

\section{$\mathrm{SIH}$}

The Survey of Income and Housing is today the main ABS survey on household incomes. It is conducted more frequently than the HES and utilises a larger sample of households. In 2009-10 the ABS conducted the HES in association with the SIH and income data are harmonised across the two surveys. As with the HES there have been frequent improvements over time in the quality of data from the SIH, both with regard to definitions and in the collection process.

While CURFs are available from the 1982 and 1986 Income Distribution Surveys (as the SIH was then called), analysis in this paper is limited to the 1990 IDS onwards. This decision is largely based on the absence of imputed estimates of income tax in these earlier surveys.

Specifically this paper used data from the 1990, 1994-1995, 1995-96, 1996-97, 1997-98, 1999-2000, 2000-01, 2002-03, 2003-04, 2005-06, 2007-08 and 2009-10 surveys. With the exception of the 1990 survey which was conducted between October to December 1990, the SIH data has been collected over a period of a year with a small sample being taken each month. In this paper no attempt to derive a single consistent series over time has been made, however where possible, overlapping series have been estimated. These have used the ABS variables which contain income data classified on previous survey bases. In these cases no attempt has been made to adjust the ABS estimate of income tax.

\section{HILDA}

The HILDA Survey is a longitudinal panel survey which commenced in 2001. The survey which has annual waves of data collection was initiated, and is funded, by the Australian government through the Department of Families, Housing, Community Services and Indigenous Affairs (FaHCSIA) (now the Department of Social Services). It is managed by the Melbourne Institute of Applied Economic and Social Research at the University of Melbourne.

No edits have been undertaken to the data as it is presented here. As noted, the results of inequality analysis based on HILDA may vary from those published in other research. This can arise because of the extent to which HILDA is subject to edits, both to data and to weights, between releases. The analysis here used the Wave 10.0 in-confidence release. The income data in this file has not been subject to top-coding. 